\title{
Multigenerational mobility in India
}

\section{Kundu, Anustup}

UNU-Wider

2021-02-12

Kundu , A \& Sen , K 2021 ' Multigenerational mobility in India ' WIDER working papers, no.

32 , vol. 2021 , UNU-Wider , Helsinki , pp. 1-28 . https://doi.org/10.35188/UNU-WIDER/2021/970-9

http://hdl.handle.net/10138/328327

https://doi.org/10.35188/UNU-WIDER/2021/970-9

unspecified

publishedVersion

Downloaded from Helda, University of Helsinki institutional repository.

This is an electronic reprint of the original article.

This reprint may differ from the original in pagination and typographic detail.

Please cite the original version. 
WIDER Working Paper 2021/32

Multigenerational mobility in India

Anustup Kundu ${ }^{1}$ and Kunal Sen ${ }^{2}$

February 2021 
Abstract: Most studies of intergenerational mobility focus on adjacent generations, and there is limited knowledge about multigenerational mobility - that is, status transmission across three generations. We examine multigenerational educational and occupational mobility in India, using a nationally representative data set, the Indian Human Development Survey, which contains information about education and occupation for three generations. We find that mobility has increased over generations for education, but not for occupation. We also find that there are stark differences across social groups, with individuals belonging to socially disadvantaged communities in India lagging behind in social progress. Multigenerational mobility for Muslims in education and occupation have decreased in comparison to Hindus over the three generations. While we find that there is an increase in educational mobility for other disadvantaged groups such as Scheduled Castes, Scheduled Tribes, and Other Backward Classes compared to General Castes, we do not find evidence of increased occupational mobility over the three generations.

Key words: multigenerational mobility, occupational mobility, educational mobility, India

JEL classification: J15, J62, O12

Note: the paper is published within the UNU-WIDER project 'Social mobility in the Global South—concepts, measures, and determinants.' As the research is part of Anustup Kundu's PhD thesis, the authors will hold copyright to facilitate publication of the thesis.

\footnotetext{
${ }^{1}$ UNU-WIDER and University of Helsinki, Helsinki, Finland, corresponding author: kundu@wider.unu.edu; ${ }^{2}$ UNU-WIDER, Helsinki, Finland and University of Manchester, Manchester, UK

This study has been prepared within the UNU-WIDER project Social mobility in the Global South-concepts, measures, and determinants.

Copyright (C) Authors 2021

Information and requests: publications@wider.unu.edu

ISSN 1798-7237 ISBN 978-92-9256-970-9

https://doi.org/10.35188/UNU-WIDER/2021/970-9

Typescript prepared by Gary Smith.
}

United Nations University World Institute for Development Economics Research provides economic analysis and policy advice with the aim of promoting sustainable and equitable development. The Institute began operations in 1985 in Helsinki, Finland, as the first research and training centre of the United Nations University. Today it is a unique blend of think tank, research institute, and UN agency—providing a range of services from policy advice to governments as well as freely available original research.

The Institute is funded through income from an endowment fund with additional contributions to its work programme from Finland, Sweden, and the United Kingdom as well as earmarked contributions for specific projects from a variety of donors.

Katajanokanlaituri 6 B, 00160 Helsinki, Finland

The views expressed in this paper are those of the author(s), and do not necessarily reflect the views of the Institute or the United Nations University, nor the programme/project donors. 
A large literature has examined the transmission of economic and social outcomes such as earnings, education, and occupation across generations (Black and Devereux 2010; Blanden 2013; Chetty et al. 2014; Corak et al. 2014; Erikson and Goldthorpe 1992). While much of the literature has focused on developed countries, an emerging literature has studied whether there is intergenerational mobility in earnings, education, and occupations for developing countries (see Iversen et al. 2019 for a review). So far, the literature has focused on the association in socioeconomic status between adjacent generations (Solon 1999, 2004). There has been relatively little research on multigenerational mobility, especially in the developing-country context (Solon 2018). Yet the study of multigenerational mobility enables us to understand to what extent inequality of opportunity has reduced in a country over time. In societies where there is dynastic transmission of wealth and social standing, intergenerational persistence of economic and social status is likely to occur, inhibiting social progress. In this paper, we examine the association in educational and occupational status across three generations of males in India.

A key limitation for the study of multigenerational mobility is a lack of good data than can span three generations (Güell et al. 2018). In the case of India, we take advantage of a nationally representative data set-the Indian Human Development Survey (IHDS) 2011-12-which asks heads of households about their father's main occupation and educational level; we can also take advantage of the fact that many households in India are multigenerational. We focus on educational and occupational mobility instead of income mobility for two reasons. First, the survey questionnaire for the IHDS asks the head of the household about their father's educational level and occupational status, not about their income. Second, in the context of developing countries, the measurement of income is problematic, given the difficulty of obtaining reliable income estimates in economies with large agrarian and informal sectors (Iversen et al. 2019).

An important issue that comes up in the study of social mobility in developing countries is the existence of significant differences in the intergenerational correlation of education and occupation between social groups, where race, caste, and ethnicity may have a larger role to play in explaining the associations between the social and economic statuses of parents and their children compared to developed countries (Funjika and Gisselquist 2020). In the Indian case, several studies have shown that intergenerational mobility is weaker for individuals from disadvantaged groups such as backward castes and tribes (Scheduled Castes and Scheduled Tribes and Other Backward Classes (SC, ST, and OBC, respectively)), from religious minorities, and for individuals based in rural areas (Gang et al. 2011; Hnatkovska et al. 2012, 2013; Krishna 2014; Mohammed 2019). We examine whether the intergenerational persistence in education and occupation has become weaker for children from SC, ST, OBC, and Muslim backgrounds compared to their parents (relative to grandparents). ${ }^{1}$ We also examine whether being in a rural or urban area makes a difference in weakening intergenerational persistence in educational and occupational status over time. To do this, we use an innovative double difference (DD) method that exploits the fact that our data spans three generations. This allows us to assess whether mobility increased for sons from SC/ST, OBC, Muslims, and urban residents in comparison with their reference groups-General Castes, Hindus, and rural residents—and relative to their fathers. ${ }^{2}$

Our data set contains over 25,000 grandfather-father-son triads. The youngest age of the fathers in our sample is 36 and the oldest age is 99 . The youngest age of the sons in our sample is 18 and the oldest

\footnotetext{
${ }^{1} \mathrm{SC}, \mathrm{ST}$, and Muslims comprise 16.2, 8.2, and 14.2 per cent of the population, respectively, according to the 2011 Census of India. The Indian Census does not collect data on OBC, but estimates of their share of the Indian population is around 54 per cent (Bayly and Bayly 1999).

${ }^{2}$ General Castes are non-SC, non-ST, and non-OBC. They are mostly represented by forward castes, and are at the upper end of the Indian caste hierarchy (Bayly and Bayly 1999).
} 
age is 75. This implies that we are able to follow our three generations from around 1913 to 2012, a period that saw significant economic, political, and social change in India, including the onset of radical economic reforms in 1991, and the launch of major affirmative action programmes for the SC, ST, and OBC (Gang et al. 2017). ${ }^{3}$ Using this large time span of our data and estimates of intergenerational correlations in education and occupation for parent-son pairs relative to grandfather-father pairs, we are able to ask the following two questions: (1) has intergenerational persistence in education and occupation weakened over time in India? (2) If so, has it weakened more for SC, ST, OBC, Muslims, and rural residents than for General Castes, Hindus, and urban residents?

We find that there has been weakening of intergenerational persistence in education, but not for occupation for son-father pairs compared to father-grandfather pairs. We also find the clear presence of a 'grandfather' effect- - the grandfather's status has an effect on the son's occupational and educational attainment, independent of the father's status. Further, we find that there are stark differences across social groups, with individuals belonging to socially disadvantaged communities in India lagging behind in social progress. Multigenerational mobility for Muslims in education and occupation have decreased in comparison to Hindus over the three generations. While we find that there is an increase in educational mobility for other disadvantaged groups such as SC, ST, and OBC compared to General Castes, we do not find evidence of increased occupational mobility over the three generations for these social groups relative to General Castes.

The rest of the paper is presented in six sections. In Section 2 we provide a brief review of the related literature. In Section 3 we discuss the data and how we construct grandfather-father and father-son pairs in occupation and education. In Section 4 we discuss the empirical strategy. In Section 5 we describe patterns of occupational and educational mobility using transition matrices. Section 6 presents the results and Section 7 concludes.

\section{Related literature}

In this section, we selectively review the literature on educational and occupational mobility, with a focus on developing countries. On educational mobility, in a seminal study, Hertz et al. (2008) pool survey data for individuals aged 20-60 across 42 countries between 1994 and 2004. They find strong persistence in educational status in Latin America and Africa, with the intergenerational regression coefficient (IGRC) being 0.79 in Latin America and 0.80 in Africa. In contrast, Nordic countries had high degrees of educational mobility, with an IGRC of 0.34 . The study also finds a substantial increase in educational mobility across the world. Similarly, for Latin America, Ferreira et al. (2012) find a notable decline in the inequality of opportunities for educational attainment in the 2000s. A more recent study by Narayan et al. (2018) studies educational mobility for cohorts born between the 1940s and 1980s for a sample of 148 countries, and finds that absolute mobility is increasing for developing countries, but declining for developed countries, while relative mobility increases in both regions. In one of the most ambitious studies of social mobility in developing-country contexts, Alesina et al. (2021) use individuallevel data from 68 censuses in 26 sub-Saharan African countries to find significant geographical variation in educational mobility. They find that a child who moves with her uneducated parents to a region with a one-standard-deviation higher intergenerational mobility than her birthplace at the age of six has a 7 percentage points higher likelihood of completing primary schooling, compared to her sibling who at the time of the move was already 11 years old. In the case of India, both Azam and Bhatt (2015) and Asher et al. (2020) find a decrease in educational persistence, as measured by the IGRC, over time. However,

\footnotetext{
3 The Constitution of India accords special preferential treatment not only to SC and ST, but also to other socially and educational disadvantaged castes, collectively known as $\mathrm{OBC}$.
} 
this decline can be explained by changes in the variance of education: rising variance of the father's education over time, with constant variance of the son's education.

With respect to occupational mobility, there are relatively few studies for developing countries, possibly due to the dearth of detailed data on the occupations of father-son pairs. An early study in this regard is that of Wu and Treiman (2007) for China. Zhao and Li (2017) study the effects of ethnicity and Hukou status on class mobility in China (see also Li 2021). In a comparison of absolute mobility among social classes in four developing countries, Heath and Zhao (2021) find that Chilean men show the highest rate of social mobility (with the rate of intergenerational stability at 28 per cent), then Egypt, China, and, finally, India (which had a rate of immobility of 68 per cent). Azam and Bhatt (2015) analyse occupational mobility in India using the IHDS, finding progressive occupational mobility by birth cohort and that mobility among SC and ST born during 1965-84 exceeds mobility among higher castes. Using data from five successive cross-sections derived from the Indian National Sample Survey Organisation, Hnatkovska et al. (2013) find that the overall probability of an occupation switch has increased from 31 per cent in 1983 to 41 per cent in 2004-05, with the switch probability for SC and ST increasing from 33 per cent to 42 cent, while for others the increase is from 30 per cent to 39 per cent.

As noted in Section 1, the previous literature has focused on educational and occupational mobility across adjacent generations. In contrast, in this paper we examine mobility in education and occupation across three generations: grandfathers, fathers, and sons. We discuss next how we construct grandfatherfather-son triads using the IHDS data for India.

We use the IHDS, which is a collaborative project between the University of Maryland, the National Council of Applied Economic Research (NCAER), Indiana University, and the University of Michigan. The IHDS is a nationally representative survey of households across India with rounds in 2004-05 and 2011-12. ${ }^{4}$ In the first round 41,554 households were surveyed. In the second round 42,152 households were surveyed and 85 per cent of the households from the first round were resurveyed. The households lost to attrition in urban and rural blocks of northeastern states were physically verified by NCAER monitors and replacement households were randomly selected in the same neighbourhood to refresh the sample, which led to 2,134 new households being included in the second round (IHDS-2). We use IHDS-2, which has the advantage of being newer, providing updated data, and including information not only about co-residents, but it also about non-residents.

\subsection{Data construction}

We focus on multigenerational mobility of male members of the household. More specifically, we look into the mobility estimates between household head's father, household head, and household head's resident and non-resident sons. We choose to focus only on the male members and not include the female members from the IHDS data for two reasons. First, women move to their husband's household after marriage in India, so the household-level information on adult women is almost exclusively on unmarried daughters. ${ }^{5}$ There is a selection-bias problem here that cannot be resolved. Note that the information on non-residents in the household module does not include married daughters, who are taken to have left the household. Second, the question on the grandparent in the IHDS does not ask about the grandmother's education and occupation, only about the grandfather's.

\footnotetext{
${ }^{4}$ A third round, IHDS-3, is ongoing and is slated for release in 2023.

5 The IHDS has a women's module that identifies women between the ages of 15 and 49 .
} 
Figure 1 showcases the grandfather-father-son links that we investigate. The primary node represents the household head's father, or generation 1 (Gen 1). Gen 1 may have more than one son, the household head, and the household head's resident and non-resident siblings, represented by the secondary nodes generation 2 head (Gen 2 Head), generation 2 resident siblings (Gen 2 RS), and generation 2 non-resident siblings (Gen 2 NRS), respectively. The household head may have sons who are co-resident and/or who are non-residents. The tertiary nodes stemming from the household head represent the generation 3 resident sons (Gen 3 RS) and generation 3 non-resident sons (Gen 3 NRS).

Figure 1: Generation tree

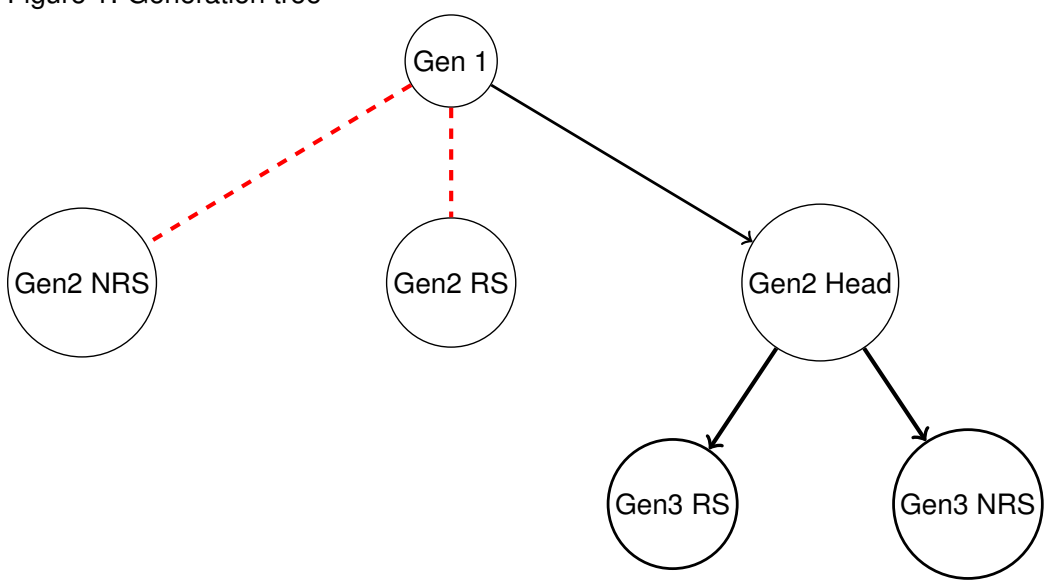

Source: authors' compilation.

The IHDS data provides detailed information on education and occupation of the male household and his resident sons. In addition, there is a separate module in the IHDS on household family members who have migrated, where information on the education and occupation of the non-resident family member, along with information on his relationship with the head of the household, is provided. This module allows us to obtain a near-complete specification of all grandfather-father-son triads (the only missing information would be for non-resident family members where education and occupation information is not available, and the information about the sons of Gen 2 NRS if they are not residing in the primary household).

Our data provides us with 21,031 observations of Gen 1-Gen 2 Head-Gen 3 RS triads and 4,310 observations of Gen 1-Gen 2 Head-Gen 3 NRS triads. Our data includes information about the resident household head as well as non-resident household heads or the household head's husband in the case of non-resident husbands of female heads. To identify the non-resident husbands with female heads, we use the non-resident family member roster. ${ }^{6}$ We used an age cut-off of 18 years for Gen 3 as by then most of the sons have completed their schooling. ${ }^{7}$ For Gen 2, we used an age cut-off of 36 years.

The primary module of IHDS-2 records the education and occupation of all the family members, including information on co-resident members and non-resident members. It records the household head's father's education and occupation even if the household head's father has died. ${ }^{8}$

\footnotetext{
${ }^{6}$ As question 1.18 asks about the primary occupation of the household's father/husband's father (for most of his life), we could identify the education and occupation of the father-in-law in the case of a household with a female head whose husband is a non-resident.

${ }^{7}$ As a robustness test, we increased the age cut-off to 21 years and found that the results not change significantly, as shown in Table 2.

${ }^{8}$ To identify the household head's father (or Gen 1) and his education and occupation we used the relationship field in the household roster and matched the information with the household head's response to the father's education and occupation question. We identify the household head (Gen 2 Head) and the Gen 3 resident sons (Gen 3 RS) using the relationship field in
} 


\subsection{Occupation}

The IHDS survey asks about different sources of household income and each member's participation in each of those work activities and their level of participation. Occupation is categorized at the two-digit level, ranging from 1 to 99 following the Indian National Classification of Occupations (NCO), which in turn draws on the International Standard Classification of Occupations (ISCO) maintained by the International Labour Organisation (ISCO-88 and its antecedents). ${ }^{9}$ The IHDS also contains created indicators for occupations such as salaried position, agriculture wage labour, non-agricultural wage labour, work in household business, family farm work, and animal care work based on whether an individual spent more than 240 hours on the particular work. In order to check if each individual's occupation is accurately categorized, we constructed variables for hours of work in salaried work, agriculture, and non-farm/business activities. We classified workers as salaried workers if they had spent more than or equal to 240 hours in wage or salary work in the past year. Farming and non-farming activity workers were classified in a similar way. We use the two-digit occupational codes given in the data for salaried workers to assign each salaried worker to their respective occupation. In the case of agricultural workers, we assign them as cultivators or farmers other than cultivators based on land owned, and we classified workers as animal care workers if they reported taking care of animals.

A limitation of the ISCO occupational schema, which were designed primarily for comparative purposes, is that it may miss some of the important institutional arrangements, anchored in history, that characterize individual developing countries (Heath and Zhao 2021). A key feature of the ISCO occupational schema is the use of skill requirements as the main principle guiding occupational rank (e.g., Armstrong 1972; Ganzeboom and Treiman 1996). In the Indian context, the translation of skill requirements into occupational status is made more intricate by caste (Gang et al. 2017). Independently of the skill requirements of their traditional, caste-based occupations, SC individuals are, for example, likely to have low social status. To categorize occupation as a social status ladder, we follow Iversen et al. (2016) and categorize occupation into six categories, as shown in Table $1 .{ }^{10}$

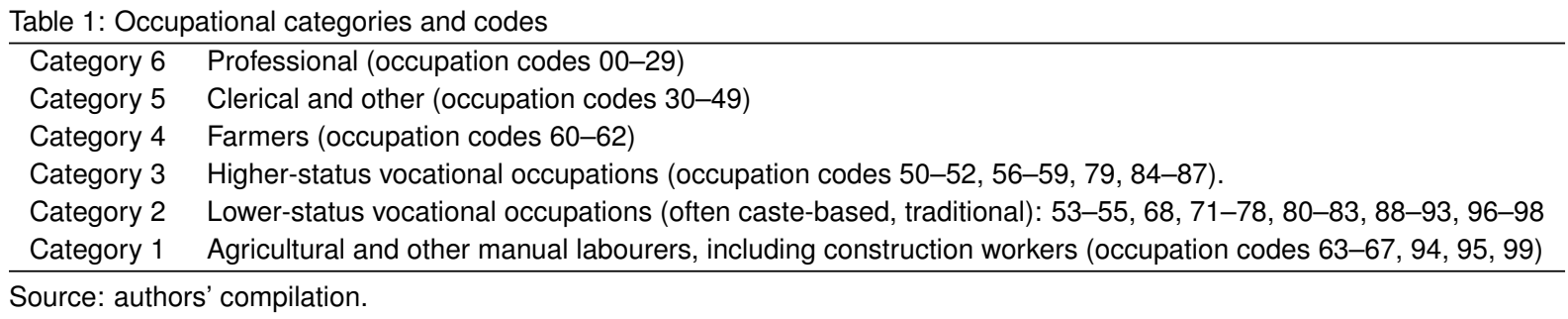

\subsection{Education}

The primary module of the IHDS records the years of education of the father of the household head, the household head, and his resident sons. The non-resident family members section of the primary module helps us to link the non-resident household head's sons (Gen 3 NRS) with the household head. The IHDS contains information on the education of the household head's father even if he is not resident or has died. In the IHDS, years of education are recorded in multiple ways, allowing us to cross-check the validity of the responses. For example, the household head's father's (Gen 1) education may be obtained from (1) the household identification; (2) the household roster (if he is a co-resident), or the non-resident family

the household roster. We use the information on non-residents to identify and link the Gen 3 non-resident sons (Gen 3 NRS) with the household head.

\footnotetext{
${ }^{9}$ Detailed in Appendix Table A7.

${ }^{10}$ Iversen et al. (2016) distinguish between vocational occupations that are skilled but low status because of a caste connotation and those that are not. Examples of low-status vocational occupations are blacksmiths and shoe-makers. Examples of highstatus vocational occupations are machinery/electrical fitters and plumbers.
} 
members (if he is a non-resident); and (3) from the household head's wife's response to the husband's father's education question. The IHDS records completed years of education. We categorize years of education into seven categories. ${ }^{11}$ The categories are (1) illiterate with less than primary (<2 years); (2) literate with less than primary (2-4 years); (3) primary; (4) middle; (5) secondary; (6) higher secondary; and (7) post-secondary. ${ }^{12}$

\section{$4 \quad$ Empirical specification}

To measure the extent of socioeconomic status transmission across generations, social scientists conventionally estimate $\beta_{-g}$ in a linear regression model such as:

$$
y_{i, t}=\alpha+\sum_{g=1}^{G} \beta_{-g} y_{i, t-g}+\varepsilon_{i, t}
$$

where $y_{i, t}$ is the socioeconomic status such as education, income, occupation, or wealth of the son of family $i$ at period $t . y_{i, t-g}$ is the socioeconomic status of the ancestral generation $g$. The coefficient $\beta_{-g}$ captures persistence, and is the IGRC, and $1-\beta_{-g}$ captures the social mobility (see Solon 2004). Equations 2.1 and 2.2 estimate intergenerational mobility in occupation and education between G2-G1 and G3-G2 pairs. The coefficients of interest are $\beta_{12}$ and $\beta_{23}$, which estimate the intergenerational persistence in occupation and education between G2-G1 and G3-G2 pairs respectively. That is, these coefficients are the IGRCs for son-father and father-grandfather mobility regressions, respectively.

$$
\begin{aligned}
& Y_{i, g_{12}}=\beta_{02}+\beta_{12} Y_{i, g-1}+\varepsilon_{i g_{12}} \\
& Y_{i, g_{23}}=\beta_{03}+\beta_{23} Y_{i, g-1}+\varepsilon_{i g_{23}}
\end{aligned}
$$

Solon (2018) proposes a three-generation version of equations (2) and (3), where we regress the son's (Gen 3) occupation or education on each ancestral generation's occupation or education:

$$
Y_{i, g}=\beta_{0}+\beta_{1} Y_{i, g-1}+\beta_{2} Y_{i, g-2}+\varepsilon_{i g}
$$

where $Y_{i, g}$ is the son's (Gen 3) occupation/education, $Y_{i, g-1}$ is the parent's (Gen 2 Head) occupation/ education, $Y_{i, g-2}$ is the grandparent's (Gen 1) occupation/education, and $\varepsilon_{i g}$ refers to the error term. The coefficients $\beta_{1}$ and $\beta_{2}$ provide estimates of intergenerational persistence across son-father and songrandfather pairs, and can be seen as IGRCs in a three-generational formulation of a Solon-type (2014) regression. Here, $\beta_{2}$ captures the 'grandfather' effect-if $\beta_{2}$ is positive and significant, it suggests that the grandfather's status has an effect on the grandson, independent of the effect of the father. ${ }^{13}$

Our dependent variables are ordered variables, with higher values implying higher occupational ranks or higher levels of educational attainment. The dependent variable for estimating occupational mobility goes from a value of 1 for agricultural and other labourers to a value of 7 for professionals. The dependent variable for estimating educational mobility goes from a value of 1 for years of education less than two years of schooling, to a value of 7 for higher education. We estimate linear probability models for equations (2), (3), and (4).

We are also interested in assessing whether intergenerational mobility among certain groups in India has increased relative to the rest of the population over the three generations. We use a DD method

\footnotetext{
11 These are standard categories used in many surveys in India, including the National Sample Surveys.

12 Similar educational categories have been used by Asher et al. (2020).

13 As Solon (2018) notes, a key prediction of the Becker and Tomes (1979) model would be that the coefficient on the grandfather's status is negative, implying that all the advantages or disadvantages of ancestors would disappear in three generations.
} 
analogous to the difference in difference (DID) method to exploit the multigenerational nature of our data and to test for differences in mobility across various groups in our sample over generations. We pool generation 1 and generation 2 to estimate

$$
Y_{i j}=\alpha+\gamma S_{i j}+\lambda G_{i j}+\rho\left(S_{i j} * G_{i j}\right)
$$

where $i$ is the son-father-grandfather triad and $j$ is the generation/time, $(j=1$ for generation $1, j=2$ for generation 2 and $j=3$ for generation 3). $Y_{i j}$ is the occupation/education of generation $j . S_{i j}$ is the location dummy (equal to 1 for urban residents), social group dummy (SC/ST, OBC), or religion dummy (Muslim) (analogous to the 'treatment' group dummy in DID). $G_{i j}$ is the generation/time dummy, which takes a value of 1 for generation 3 and 0 for generations 1 and 2 (analogous to the 'treatment' dummy in DID). $S_{i j} * G_{i j}$ is the interaction term, analogous to the 'treatment effect' in a DID model.

The coefficient $\alpha$ shows the average $Y$ in the 'non-treated' group in the 'pre-treatment' period. $\gamma$ shows the difference between the 'treatment' group and the 'control' group in the 'pre-treatment' period. $\lambda$ captures the change in $Y$ between the 'pre-treatment' and the 'treatment' period. $\rho$ captures the change in $Y$ in the 'treatment' group between the 'pre-treatment' and the 'treatment' period, relative to the change in $Y$ in the 'control' group, and is the coefficient of interest. If the coefficient on the interaction term is positive and statistically significant, multigenerational mobility has increased for the 'treatment' group (urban, SC/ST, OBC, Muslim) relative to the 'control' group (rural for the urban 'treatment' group, General Caste for OBC and SC/ST 'treatment' groups, and Hindus for the Muslim 'treatment' group). We cluster the standard errors at the household level.

\section{$5 \quad$ Patterns of occupational and educational mobility}

\subsection{Occupation}

For an initial look at patterns of occupational mobility, we construct a $6 \times 6$ transition matrix. Figure 2 shows occupational mobility between the three generations. The top-left panel of Figure 2 shows the occupational mobility between generation 1 (household head's father) and generation 2 head (household head), while the top-right panel of the figure shows occupational mobility between the generation 2 head and generation 3 son (household head's son), and the bottom-left panel shows the occupational mobility between generation 1 and generation 3 . The vertical axis shows the occupation of the younger generation, conditional on the occupation of the older generation, depicted in the horizontal axis. If we look at the top-left panel of Figure 2 or Appendix Table A1, for father-grandfather pairs, we can see that 39.1 per cent of professionals' sons are in professional occupations, 54.9 per cent of clerical workers' sons are in clerical jobs, 46.3 per cent of farmers' sons are farmers, 37.3 per cent of high-skilled labourers' sons are high-skilled labourers, 48.8 per cent of low-skilled labourers' sons are low-skilled labourers, and 57.5 per cent of agricultural labourers' sons are agricultural labourers. For son-father pairs, we find that 46.1 per cent of professionals' sons are in professional occupations, 48.1 per cent of clerical workers' sons are in clerical jobs, 39.4 per cent of farmers' sons are farmers, 32.9 per cent of high-skilled labourers sons are high-skilled labourers, 45.1 per cent of low-skilled labourers' sons are low-skilled labourers, and 60 per cent of agricultural labourers' sons are agricultural labourers.

A striking finding from the transition matrix for the overall sample is the stickiness of occupations at both the upper and lower ends of the occupational status ranking. For example, at the upper end of the occupational distribution, 39 per cent of the sons of the G1 generation who are professionals remain professionals, and this increases to 46.1 per cent for the G3-G2 pair. At the lower end of the occupational distribution, 57.5 per cent of the sons of the G1 generation who were agricultural and other labourers remain in the same occupational status, and this increases to 60 per cent for the G3-G2 pair. Over time, there is some evidence of upward occupational mobility - for example, 7.1 per cent of the grandsons of 
the G1 generation who were agricultural and other labourers become professionals, compared to 4.1 per cent of the sons of the G2 generation. Similarly, 10.5 per cent of the grandsons of the G1 generation who were low-skilled workers become professionals as compared to 6.3 per cent of the sons of the G2 generation.

Figure 2: Occupational mobility across generations
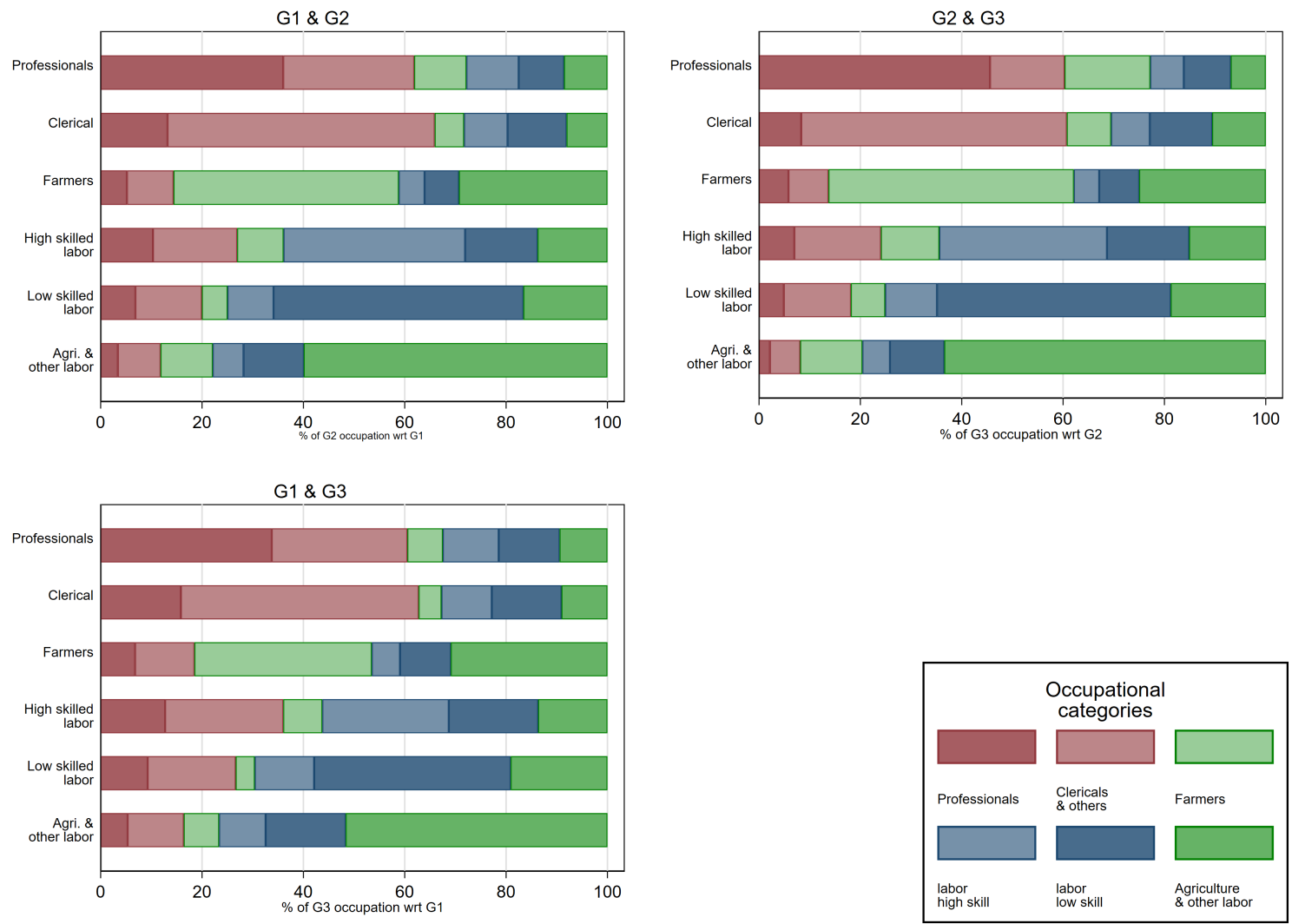

Source: authors' compilation based on IHDS data.

In Appendix Figure $\mathrm{C} 2$ we present the distribution of occupational rankings across states in India for generations 1,2 , and 3. It is clear that there is large geographical variation in occupational status across India, with higher occupational status for generation 1 in western and eastern India, as compared to other regions. Over the three generations, one can see a significant increase in occupational status in northwest India, but also a decrease in occupational status in western India.

Disaggregating the occupational mobility matrices by location and across religion and caste, we see significant upward mobility for the grandsons of the G1 generation who were at the lower end of the occupational status ranking (agricultural and other labourers and low-skilled workers) for the urban sample as compared to the rural sample (Figure 3). Across religion, we do not see any clear differences in upward mobility for Hindus versus Muslims and other religions (Figure 4). However, we see clear intergenerational persistence in occupational status at the lower end of the occupational ranking for OBCs and SC/STs compared to General Castes over time (Figure 5). 
Figure 3: Occupational mobility across location over generations
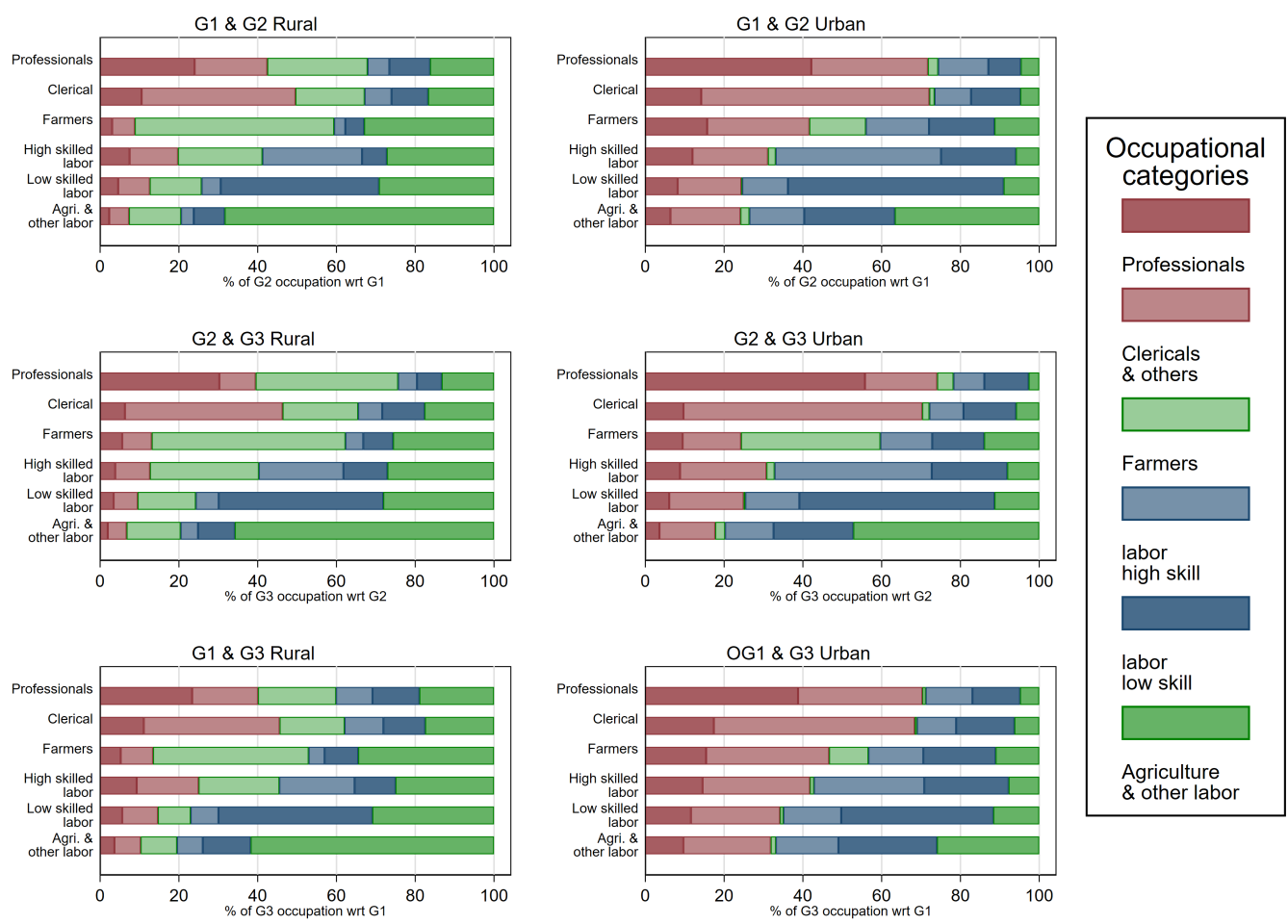

Source: authors' compilation based on IHDS data.

Figure 4: Occupational mobility across religion over generations
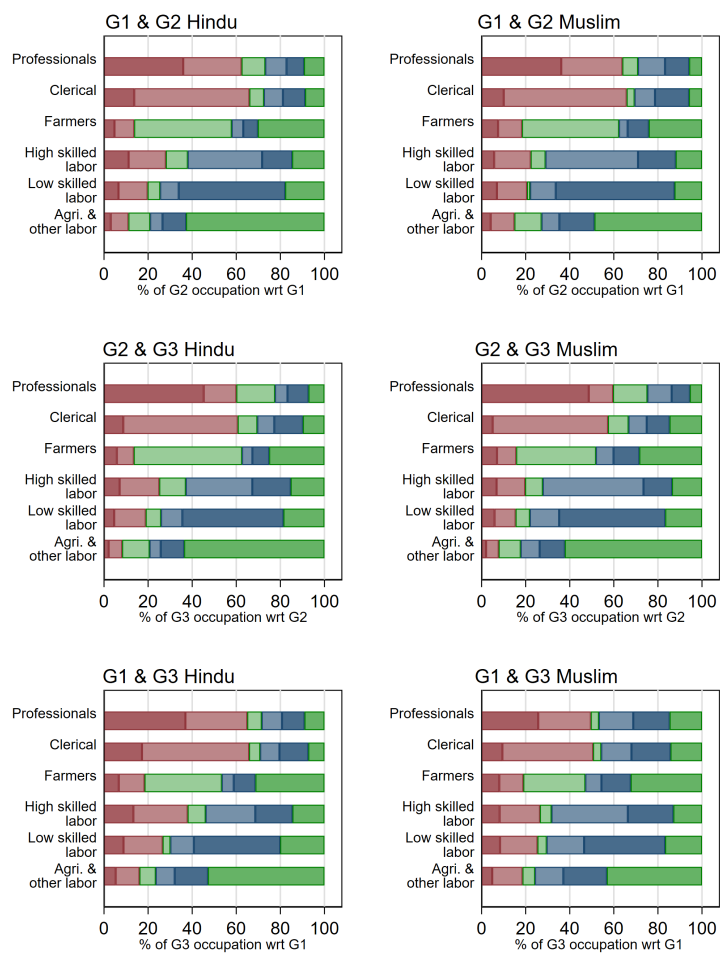

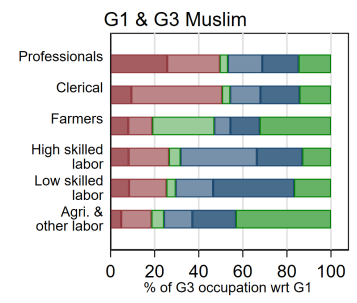

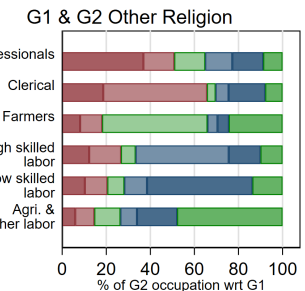

G2 \& G3 Other religion

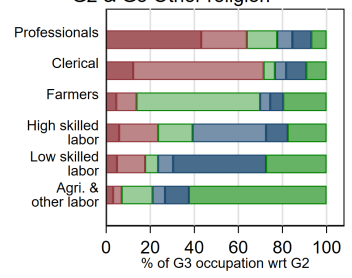

G1 \& G3 Other religion

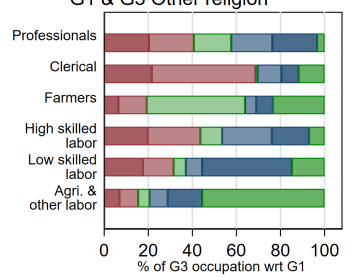

Occupational categories

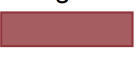

Professionals $\square$

Clericals \& others

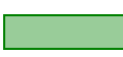

Farmers

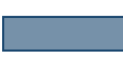

labor

high skil

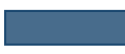

labor

low skill

Agriculture

\& other labor

Source: authors' compilation based on IHDS data. 
Figure 5: Occupational mobility across caste over generations
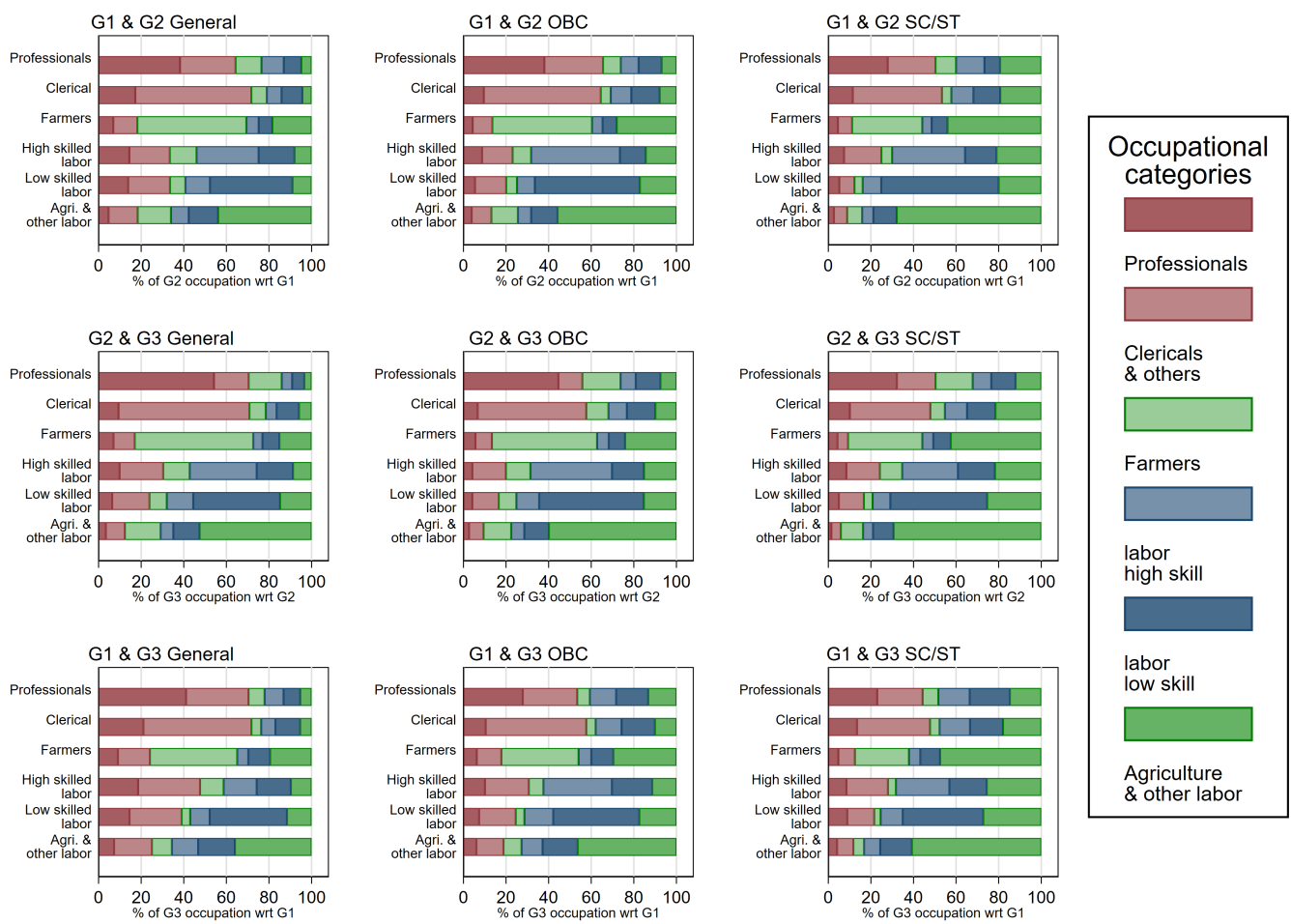

Source: authors' compilation based on IHDS data.

\subsection{Education}

For an overview of the data and patterns in mobility, we categorize years of education into seven categories: (1) illiterate with less than primary; (2) literate with less than primary; (3) primary; (4) middle; (5) secondary; (6) higher secondary; and (7) post-secondary. We construct a $7 \times 7$ transition matrix. Figure 6 shows educational mobility between the three generations. The top-left panel of the figure depicts the educational mobility between generation 1 (household head's father) and generation 2 head (household head), while the top-right panel shows educational mobility between generation 2 head and generation 3 son (household head's son), and the bottom-left panel shows educational mobility between generation 1 and generation 3. The vertical axis in Figure 6 shows the educational attainment of the younger generation conditional on the educational attainment of the older generation, depicted in the horizontal axis. If we compare the top-left and top-right panels of Figure 6, we see that there has been a significant drop in educational attainment between generation 2 and generation 3 for the top three educational categories. This difference is even more prominent if we look at Appendix Tables A4 and A5. However, at the lower end of the educational attainment distribution, we see substantial progress in educational mobility - the proportion of male children who have pre-primary or no years of education similar to their fathers has reduced considerably as we move from the father-grandfather pair to the son-father pair. While 43 per cent of the sons (generation 2) of the first generation who had no or preprimary level of education also had no or pre-primary level of education, the corresponding number was 14.3 per cent for the G3-G2 pair. For the grandfathers who had no or pre-primary level of education, a remarkable 29 per cent of their grandsons had attained higher education.

In Appendix Figure $\mathrm{C} 1$ we present the distribution of educational levels across states in India for generations 1, 2, and 3. Educational levels vary considerable across India for the same generation. Over time, there is an increase in educational levels over the three generations in western and southern India. 

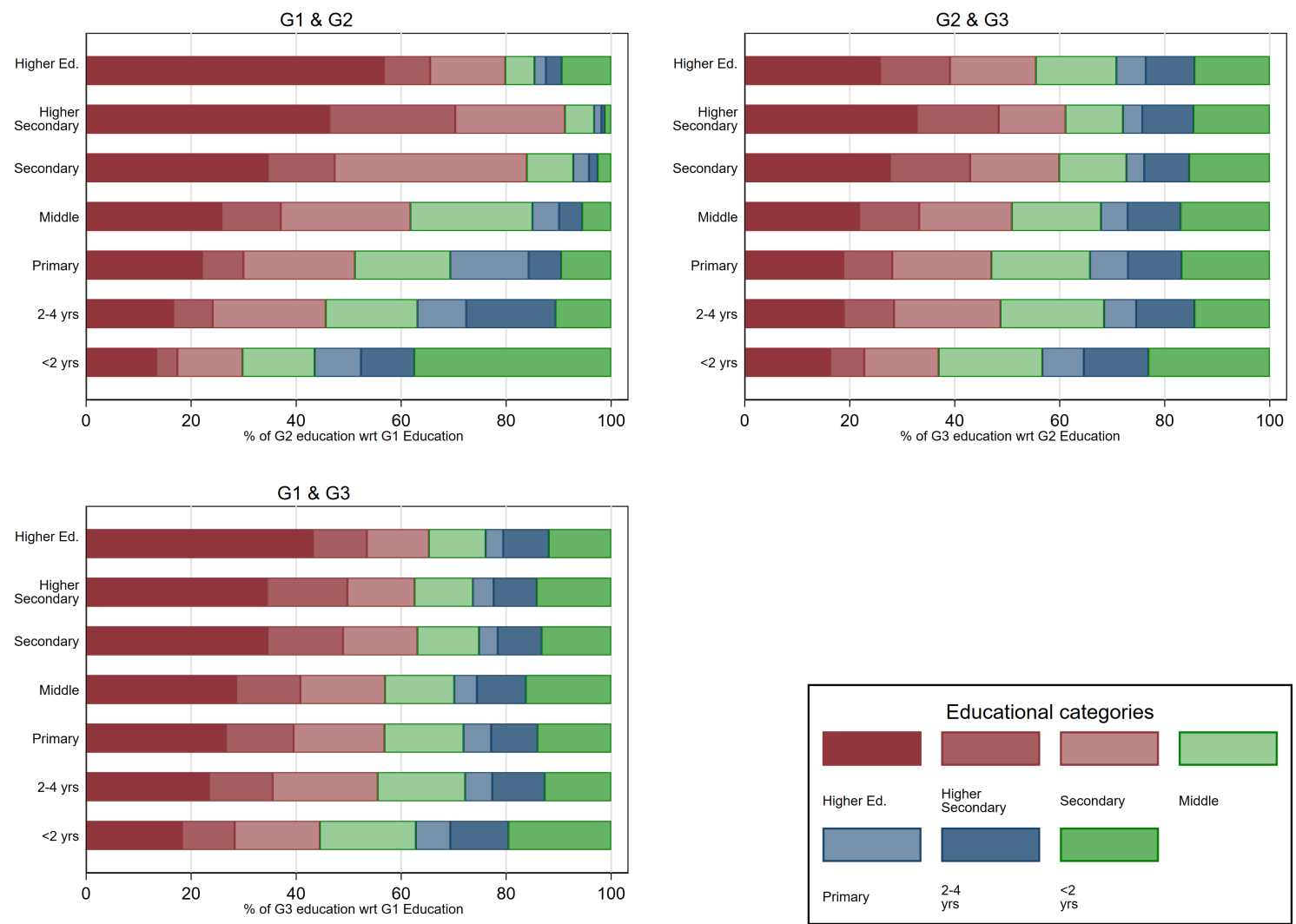

Source: authors' compilation based on IHDS data.

We next look at patterns of educational mobility by location, and across religion and caste. We find that multigenerational mobility is more evident for urban residents than rural residents at the lower end of the educational attainment distribution (no or pre-primary level of education) and multigenerational persistence is more evident for the higher end of the educational attainment distribution (higher education or higher secondary levels of education) (Figure 7). We find that the intergenerational persistence in education levels at the lower level of the educational attainment distribution (no or pre-primary level of education) has reduced over time for Hindus and other religions (Christians and Sikhs), but less so in the case of Muslims (Figure 8). Finally, across caste, we do not find any observable differences in multigenerational mobility across General Castes, OBC, and SC/ST. All three caste groups have seen educational mobility at the lower end of the educational attainment distribution (no or pre-primary level of education) across the three generations (Figure 9). 
Figure 7: Educational mobility across location over generations
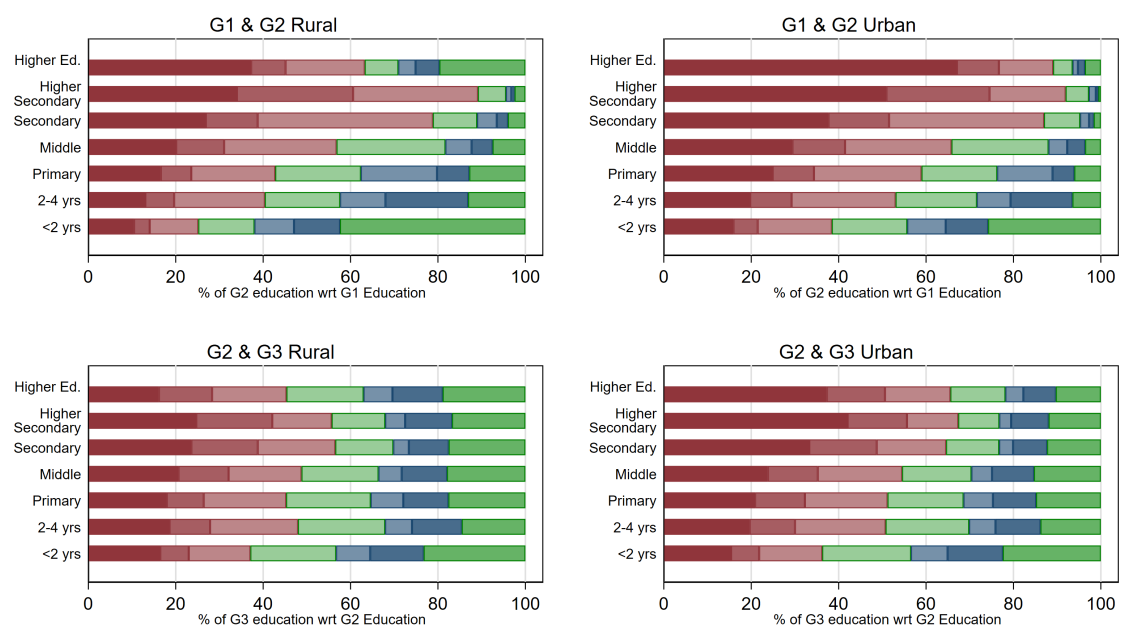

G1 \& G3 Rural

G1 \& G3 Urban
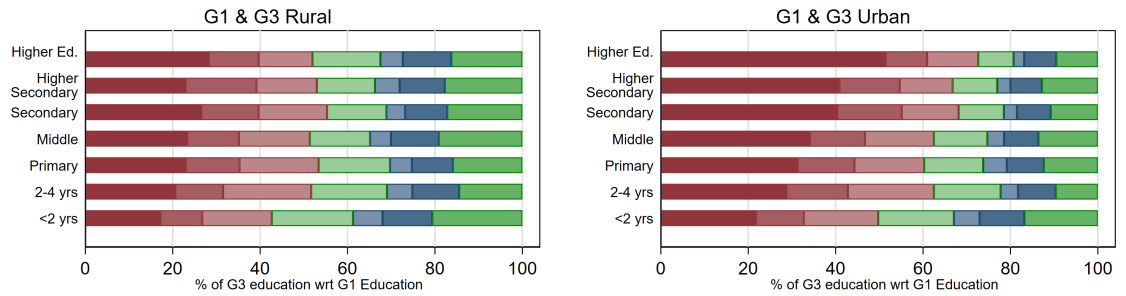

Educationa

categories

Higher Ed.

(

Higher

Secondary

$\square$

Secondary

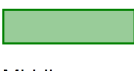

Middle

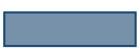

Primary

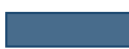

$2-4$

(n)

$<2$

yrs

Source: authors' compilation based on IHDS data.

Figure 8: Educational mobility across religion over generations
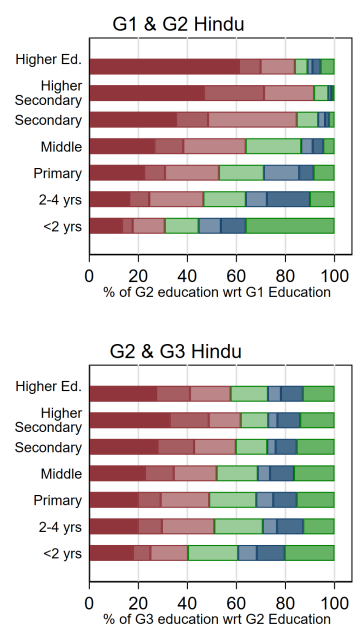

G1 \& G3 Hindu

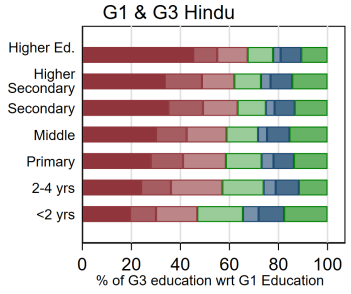

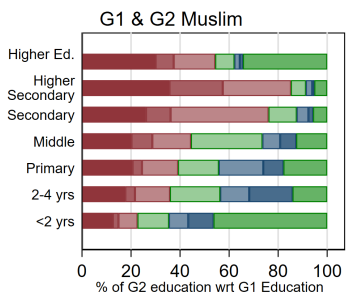

G2 \& G3 Muslim

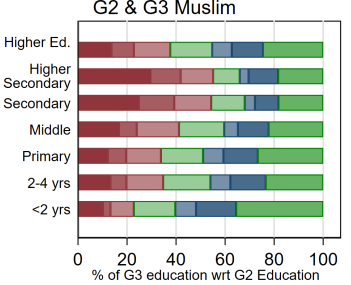

G1 \& G3 Muslim

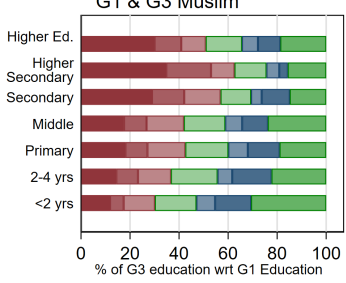

G1 \& G2 Other Religion

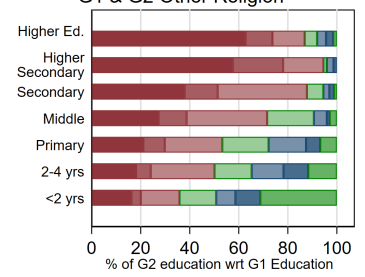

G2 \& G3 Other religion

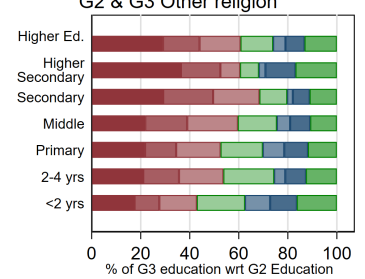

G1 \& G3 Other religion

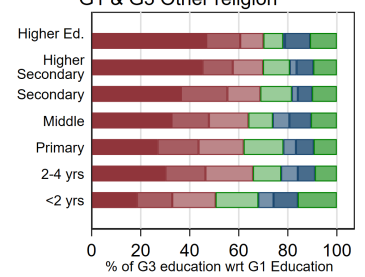

Educational categories

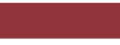

Higher Ed.

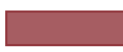

Higher

Secondary

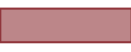

Secondary

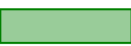

Middle

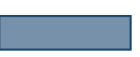

Primary

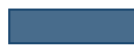

$2-4$
yrs

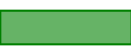

$<2$
yrs

Source: authors' compilation based on IHDS data. 
Figure 9: Educational mobility across caste over generations
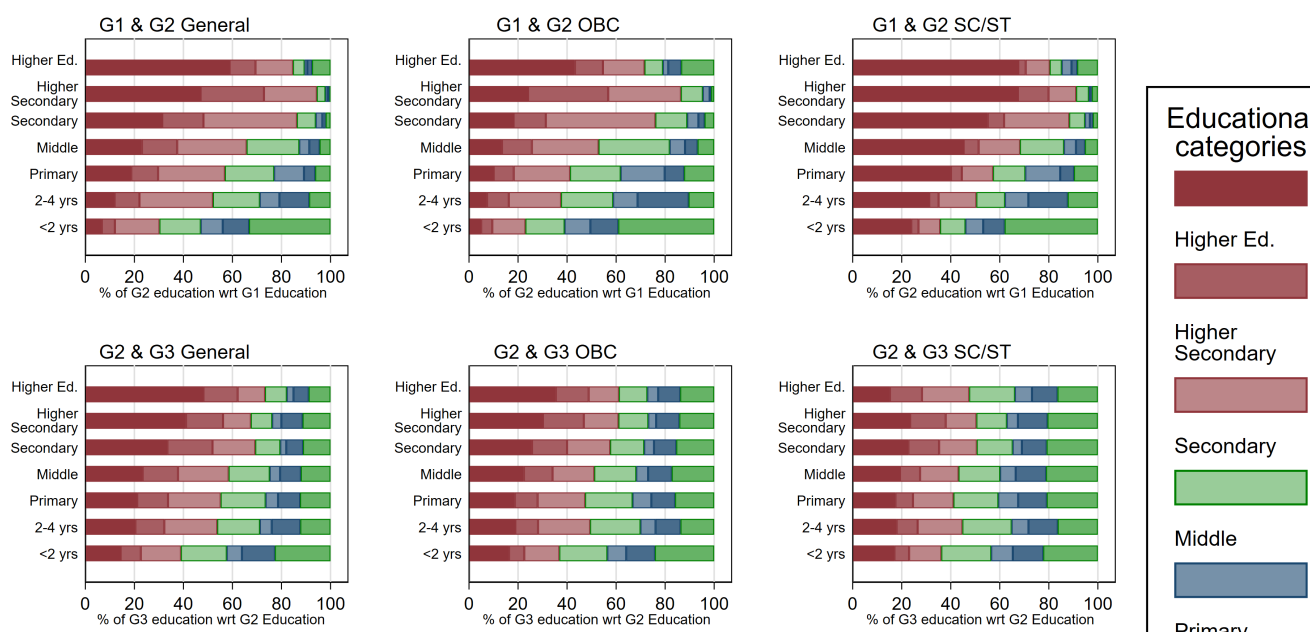

Higher Ed
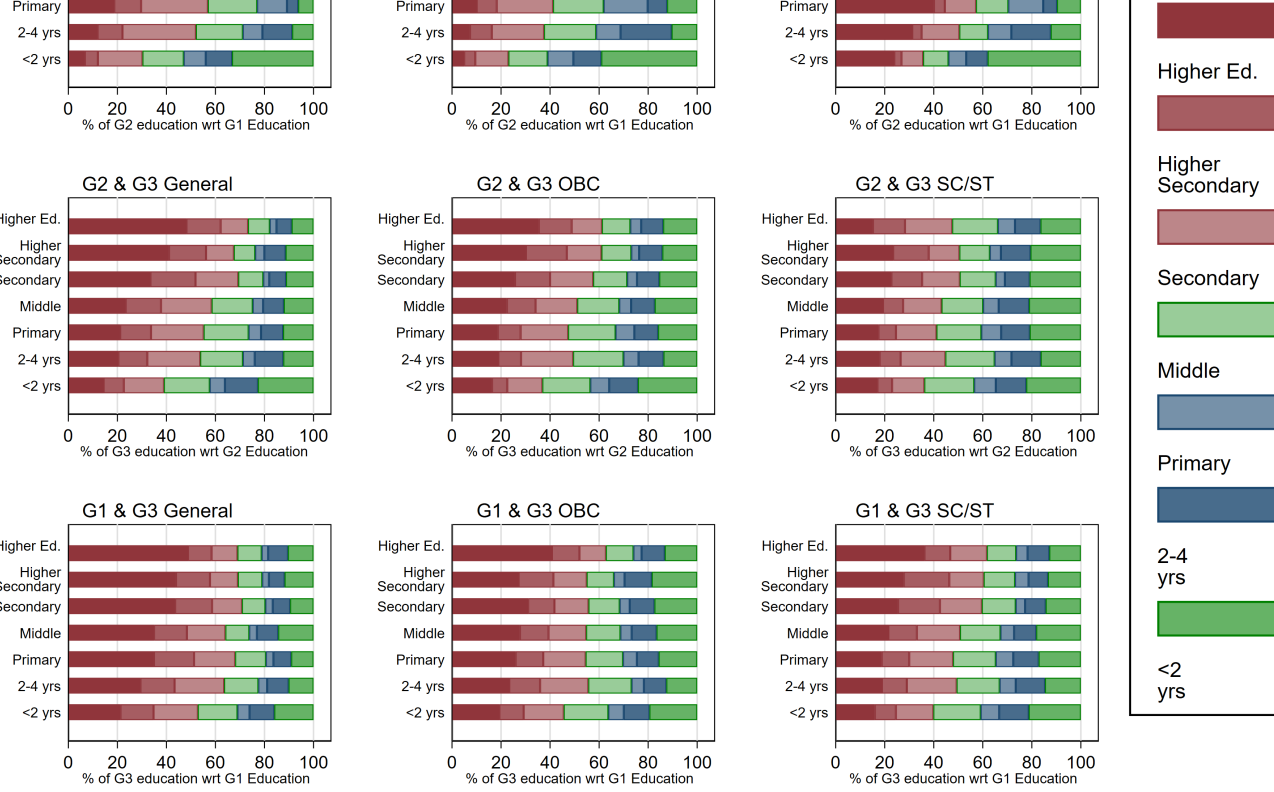

Higher
Secondary

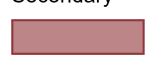

Secondary

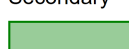

Middle

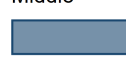

Primary

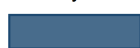

$2-4$

yrs

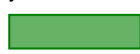

$<2$

yrs

Source: authors' compilation based on IHDS data.

\section{Results}

Table 2 presents the estimation results using equations (2.1), (2.2), and (3). In columns 1 and 2 we estimate equations (2.1) and (2.2) for occupational mobility. In columns 3 and 4 we estimate equations (2.1) and (2.2) for educational mobility. We do not find evidence of increased occupational mobility over the three generations, with the IGRC for the son-father pair being higher than the IGRC for the father-grandfather pair. Specifically, the coefficient for occupational mobility for the fathergrandfather pair is 0.423 (column 1), while the coefficient for occupational mobility for the son-father pair is 0.461 (column 2), both being statistically significant at the 1 per cent level. On the other hand, we find evidence of educational mobility across the three generations, with the IGRCs decreasing from the father-grandfather pair to the son-father pair. Specifically, the coefficient for educational mobility for the father-grandfather pair is 0.587 (column 3), while the coefficient for educational mobility for the son-father pair is 0.356 (column 4), both being statistically significant at the 1 per cent level.

Estimating the three-generation version of the mobility regressions (equation (3)), we find clear evidence of a 'grandfather' effect in both occupational and educational mobility. The estimated coefficient on the grandfather's occupational status is 0.123 and is statistically significant at the 1 per cent level for occupational mobility (column 5). Similarly, the estimated coefficient on the grandfather's educational status is 0.0649 and is statistically significant at the 1 per cent level for educational mobility (column 7). If we increase the age cut-off from 18 to a higher age, say 21 years, the estimates do not change significantly for occupational and educational mobility (columns 6 and 8). Therefore, there is evidence for India 
that the impact of family background characteristics on occupational and educational attainment goes beyond the parental generation. ${ }^{14}$

\begin{tabular}{|c|c|c|c|c|c|c|c|c|}
\hline & $\begin{array}{c}(1) \\
G 2 O C C\end{array}$ & $\begin{array}{c}(2) \\
G 3 \mathrm{occ}\end{array}$ & $\begin{array}{c}\text { (3) } \\
\text { G2 edu }\end{array}$ & $\begin{array}{c}(4) \\
\text { G3 edu }\end{array}$ & $\begin{array}{c}\text { (5) } \\
\text { G3 occ. }>18\end{array}$ & $\begin{array}{c}(6) \\
G 3 \text { occ }^{\prime}>21\end{array}$ & $\begin{array}{c}(7) \\
\text { G3 edu }>18\end{array}$ & $\begin{array}{c}\text { (8) } \\
\text { G3 edu }>21\end{array}$ \\
\hline G1 occ. & $0.423^{* * *}$ & & & & $0.123^{* * *}$ & $0.118^{* * *}$ & & \\
\hline & (0.00754) & & & & $(0.00971)$ & $(0.0118)$ & & \\
\hline G2 occ. & & $\begin{array}{c}0.461^{* * *} \\
(0.00806)\end{array}$ & & & $\begin{array}{c}0.422^{* * *} \\
(0.00863)\end{array}$ & $\begin{array}{l}0.426^{* * *} \\
(0.0105)\end{array}$ & & \\
\hline G1 edu. & & & $\begin{array}{c}0.587^{* * *} \\
(0.00739)\end{array}$ & & & & $\begin{array}{l}0.0649^{* * *} \\
(0.00739)\end{array}$ & $\begin{array}{l}0.0696^{* * * *} \\
(0.00900)\end{array}$ \\
\hline G2 edu. & & & & $\begin{array}{c}0.356^{* * *} \\
(0.00503)\end{array}$ & & & $\begin{array}{c}0.334^{* * *} \\
(0.00562)\end{array}$ & $\begin{array}{c}0.349^{* * *} \\
(0.00687)\end{array}$ \\
\hline Constant & $\begin{array}{l}1.729^{* * *} \\
(0.0265)\end{array}$ & $\begin{array}{l}1.594^{* * *} \\
(0.0273)\end{array}$ & $\begin{array}{c}2.173^{* * *} \\
(0.0181)\end{array}$ & $\begin{array}{l}4.118^{* * *} \\
(0.0194)\end{array}$ & $\begin{array}{l}1.323^{* * *} \\
(0.0344)\end{array}$ & $\begin{array}{l}1.370^{* * *} \\
(0.0425)\end{array}$ & $\begin{array}{l}4.066^{* * *} \\
(0.0202)\end{array}$ & $\begin{array}{l}3.984^{* * *} \\
(0.0246)\end{array}$ \\
\hline Obs. & 19,592 & 13,970 & 25,341 & 25,341 & 13,907 & 10,333 & 25,341 & 17,688 \\
\hline
\end{tabular}

Note: standard errors in parentheses. ${ }^{*} p<0.05,{ }^{* *} p<0.01,{ }^{* *} p<0.001$.

Source: authors' compilation based on IHDS data.

We next look into the DD estimation results using equation (4). Table 3 presents the estimation results. The first half of the table provides the estimates of equation (3) for occupational and educational mobility for different 'treatment' groups-first, Muslims, next SC/ST, followed by urban residents, and, finally, OBCs. The second half of the table provides the mean values of occupational ranks and educational attainment levels 'pre-treatment' and 'post-treatment' for the 'treatment' and 'control' groups. Columns 1 and 2 present estimates for Muslims relative to Hindus, first for education and then for occupation. If we look at the first column, time $(\lambda)$ captures the change in educational attainment for the 'control' group (Hindus) between 'pre-treatment' $\left(T_{0}\right)$ and 'treatment' $\left(T_{1}\right)$ periods. Muslim $(\gamma)$ captures the change in educational attainment between the 'control' group (Hindus) and the treated group (Muslims) during the 'pre-treatment' $\left(T_{0}\right)$ period. $\rho$ captures the group and time $S_{i j} * G_{i j}$ interaction effect (the DID term), which is the difference of change in educational attainment for the 'treatment' group (Muslims) between the 'pre-treatment' $\left(T_{0}\right)$ and 'treatment' $\left(T_{1}\right)$ periods, relative to the change in the educational attainment for the 'control' group between the 'pre-treatment' $\left(T_{0}\right)$ and 'treatment' $\left(T_{1}\right)$ periods. The constant term $(\alpha)$ captures the average educational attainment of the 'control' group in the 'pre-treatment' $\left(T_{0}\right)$ period.

For columns 3 and 4, SC/ST $(\gamma)$ captures the change in educational attainment between the 'control' group (General Castes) and the treated group (SC/ST) during the 'pre-treatment' $\left(T_{0}\right)$ period. For columns 5 and 6, location $(\gamma)$ captures the change in educational attainment between the 'control' group (rural) and the treated group (urban) during the 'pre-treatment' $\left(T_{0}\right)$ period. Lastly, for columns 7 and 8 , OBC $(\gamma)$ captures the change in educational attainment between the 'control' group (General Castes) and the treated group $(\mathrm{OBC})$ during the 'pre-treatment' $\left(T_{0}\right)$ period. Finally, in all these cases, the coefficient $(\rho)$ on the interaction term $S_{i j} * G_{i j}$ captures the 'treatment effect', where the 'treatment' group is SC/ST for columns 3 and 4, urban residents for columns 5 and 6, and OBC for columns 7 and 8.

The second half of Table 3 presents the mean values of 'control' and 'treatment' groups at time $T_{0}$ (that is, generations 1 and 2) and time $T_{1}$ (that is, generation 3), and the differences between these mean values at time $T_{0}$ and time $T_{1}$. That is, we are comparing the differences of educational attainment/occupational ranking of Muslims, SC/ST, OBC, and urban residents with those of Hindus, General Castes (who are the 'control' group for both SC/ST and $\mathrm{OBC}$ ), and rural residents for generations 1 and 2 with generation 3.

14 Our finding that the grandfather's occupation matters, even after controlling for the father's occupation, is similar to that of Long and Ferrie (2018) for Britain and the USA, which is one of the few studies to examine multigenerational mobility. 
Table 3: Multigenerational education and occupational mobility DD

\begin{tabular}{|c|c|c|c|c|c|c|c|c|}
\hline Variables & $\begin{array}{c}\text { (1) } \\
\text { G3 edu }\end{array}$ & $\begin{array}{c}\text { (2) } \\
\text { G3 occ. }\end{array}$ & $\begin{array}{c}\text { (3) } \\
\text { G3 edu. }\end{array}$ & $\begin{array}{c}\text { (4) } \\
\text { G3 occ. }\end{array}$ & $\begin{array}{c}\text { (5) } \\
\text { G3 edu. }\end{array}$ & $\begin{array}{c}\text { (6) } \\
\text { G3 occ. }\end{array}$ & $\begin{array}{c}\text { (7) } \\
\text { G3 edu. }\end{array}$ & $\begin{array}{c}\text { (8) } \\
\text { G3 occ. }\end{array}$ \\
\hline Time $(\lambda)$ & $\begin{array}{l}2.269^{\star * \star} \\
(0.0142)\end{array}$ & $\begin{array}{c}0.0212 \\
(0.0163)\end{array}$ & $\begin{array}{l}1.952^{* \star \star} \\
(0.0228)\end{array}$ & $\begin{array}{l}0.00511 \\
(0.0260)\end{array}$ & $\begin{array}{l}2.378^{* * \star} \\
(0.0159)\end{array}$ & $\begin{array}{c}-0.0961^{* * *} \\
(0.0172)\end{array}$ & $\begin{array}{l}1.952^{\star \star *} \\
(0.0228)\end{array}$ & $\begin{array}{l}0.00511 \\
(0.0260)\end{array}$ \\
\hline Muslim $(\gamma)$ & $\begin{array}{c}-0.346^{* * *} \\
(0.0269)\end{array}$ & $\begin{array}{r}-0.00737 \\
(0.0260)\end{array}$ & & & & & & \\
\hline $\begin{array}{l}\text { Group * time }(\rho) \\
\text { (rel,caste,location) }\end{array}$ & $\begin{array}{c}-0.422^{* * *} \\
(0.0429)\end{array}$ & $\begin{array}{c}-0.0949^{* *} \\
(0.0454)\end{array}$ & $\begin{array}{l}0.426^{* * *} \\
(0.0333)\end{array}$ & $\begin{array}{l}-0.0413 \\
(0.0370)\end{array}$ & $\begin{array}{l}-0.525^{* * *} \\
(0.0271)\end{array}$ & $\begin{array}{l}0.378^{* * *} \\
(0.0310)\end{array}$ & $\begin{array}{l}0.272^{* * *} \\
(0.0308)\end{array}$ & $\begin{array}{c}0.0268 \\
(0.0345)\end{array}$ \\
\hline $\mathrm{SC} / \mathrm{ST}(\gamma)$ & & & $\begin{array}{c}-1.228^{\star * *} \\
(0.0225)\end{array}$ & $\begin{array}{c}-1.159^{\star * *} \\
(0.0197)\end{array}$ & & & & \\
\hline Location $(\gamma)$ & & & & & $\begin{array}{l}1.176^{* * *} \\
(0.0185)\end{array}$ & $\begin{array}{l}0.584^{* * *} \\
(0.0172)\end{array}$ & & \\
\hline $\mathrm{OBC}(\gamma)$ & & & & & & & $\begin{array}{c}-0.798^{* * *} \\
(0.0219)\end{array}$ & $\begin{array}{r}-0.606^{* * *} \\
(0.0184)\end{array}$ \\
\hline Constant $(\alpha)$ & $\begin{array}{l}2.761^{* * *} \\
(0.00991)\end{array}$ & $\begin{array}{l}3.040^{* * *} \\
(0.00885)\end{array}$ & $\begin{array}{l}3.428^{* * *} \\
(0.0176)\end{array}$ & $\begin{array}{l}3.639^{* * *} \\
(0.0139)\end{array}$ & $\begin{array}{l}2.326^{* * *} \\
(0.00955)\end{array}$ & $\begin{array}{l}2.845^{\star \star \star} \\
(0.00936)\end{array}$ & $\begin{array}{l}3.428^{* * *} \\
(0.0176)\end{array}$ & $\begin{array}{l}3.639^{* * *} \\
(0.0139)\end{array}$ \\
\hline Observations & 85,020 & 72,579 & 54,187 & 45,995 & 91,288 & 77,715 & 64,684 & 54,523 \\
\hline Mean control $\left(T_{0}\right)$ & 2.761 & 3.040 & 3.428 & 3.639 & 2.326 & 2.845 & 3.428 & 3.639 \\
\hline Mean treated $\left(T_{0}\right)$ & 2.414 & 3.033 & 2.200 & 2.480 & 3.502 & 3.429 & 2.630 & 3.033 \\
\hline $\operatorname{Diff}\left(T_{0}\right)$ & -0.346 & -0.00737 & -1.228 & -1.159 & 1.176 & 0.584 & -0.798 & -0.606 \\
\hline Mean control $\left(T_{1}\right)$ & 5.030 & 3.061 & 5.380 & 3.644 & 4.704 & 2.749 & 5.380 & 3.644 \\
\hline Mean treated $\left(T_{1}\right)$ & 4.262 & 2.959 & 4.578 & 2.444 & 5.356 & 3.711 & 4.854 & 3.065 \\
\hline $\operatorname{Diff}\left(T_{1}\right)$ & -0.768 & -0.102 & -0.802 & -1.200 & 0.651 & 0.963 & -0.526 & -0.579 \\
\hline
\end{tabular}

Note: robust standard errors in parentheses clustered at the household level. ${ }^{* * *} p<0.01,{ }^{* *} p<0.05,{ }^{*} p<0.1$.

Source: authors' compilation based on IHDS data.

From Table 3, if we look at columns 1 and 2 we see that, over time, the average educational and occupational attainment for the 'control' group (Hindus) has increased by 2.269 (from 2.761 to 5.030) and 0.0212 (from 3.040 to 3.061), respectively. For the 'pre-treatment' ( $\left.T_{0}\right)$ (generations 1 and 2), the 'treated' group (Muslims) in comparison to the 'control' group (Hindus) on average has lower educational and occupational attainments by 0.346 and 0.0073 , respectively. These increase to 4.262 and 2.959 in generation 3. However, the increase in occupational ranking and educational attainment for Muslims is not as much as those for Hindus over the three generations. Therefore, the coefficient $(\rho)$ of the interaction terms $S_{i j} * G_{i j}$ is negative and significant for both education and occupation in columns 1 and 2, respectively. This implies that Muslims have seen weakening intergenerational mobility over time in education and occupations compared to Hindus. Our results imply that Muslims over time on average have lower educational and occupational attainment by 0.422 and 0.0949 points in comparison to Hindus, captured by $\rho$.

Columns 3 and 4 presents estimates for SC/ST relative to General Castes, first for education and then for occupation. We find that over time the average educational and occupational attainment for the 'control' group (General Castes) has increased by 1.952 (from 3.428 to 5.380) and 0.0051 (from 3.639 to 3.644), respectively. For the 'pre-treatment' $\left(T_{0}\right)$ period, the 'treated' group (SC/ST) in comparison to the 'control' group (General Castes) on average has a lower educational attainment and occupational ranking by 1.228 and 1.159, respectively. However, the difference in educational attainment between SC/ST and General Castes narrowed in the treatment period $\left(T_{1}\right)$ to 0.802 , but increased for occupational ranking to 1.200. Therefore, we see that educational mobility has increased for SC/ST relative to General Castes over the three generations, with the coefficient on the interaction effect positive and significant-there is a 0.426 point increase in occupational ranking for SC/ST compared to General Castes. In contrast, there is no evidence of increased occupational mobility across generations for SC/ST - the interaction term for the occupational mobility estimate (column 4) is statistically insignificant (and negative). Our finding of an increase in educational mobility for SC/ST relative to General Castes over the three generations 
is consistent with the finding of higher educational mobility for SC in the work of Asher et al. (2020) in the two-generation case. On the other hand, our findings on the lack of an increase in occupational mobility in the multigenerational case contrasts with the finding of greater occupational mobility among SC/ST by Azam (2015) in the two-generation case. ${ }^{15}$

We next look at educational and occupational mobility across the three generations for urban versus rural residents. Columns 5 and 6 present estimates for the urban group relative to the rural group, first for education and then for occupation. We see that over time the average educational attainment for the rural group has increased by 2.378 (from 2.326 to 4.704), but occupational attainment has decreased by 0.0961 (from 2.845 to 2.749 ). For the 'pre-treatment' $\left(T_{0}\right)$ period, the urban group has a higher education and occupational attainment by 1.176 and 0.584 , respectively. However, over time the urban group in comparison to the rural group on average has a lower educational attainment by 0.525 but a higher occupational attainment of 0.378 , which is captured by $\rho$. Therefore, we find that multigenerational educational mobility has weakened for urban residents relative to rural residents (the coefficient on the interaction term is negative and significant), while occupational mobility has increased (the coefficient on the interaction term is positive and significant). The weakening of educational mobility can be attributed to the fact that there has been a large increase in schooling in rural India over time, which means children in rural households have been receiving more education, catching up to the schooling levels of children in urban households (Dréze and Kingdon 2001).

Finally, we look at multigenerational educational and occupational mobility of OBCs compared to General Castes in columns 7 and 8 , respectively. Columns 7 and 8 present estimates for OBC relative to General Castes, first for education and then for occupation. We see that over time the average educational and occupational attainment for General Castes has increased by 1.952 (from 3.428 to 5.380) and 0.00511 (from 3.639 to 3.644 ), respectively. For the 'pre-treatment' $\left(T_{0}\right)$ period, OBC caste in comparison to the general caste on average has a lower educational and occupational attainment by 0.798 and 0.606, respectively. Similar to the case of SC/ST, we find that multigenerational educational mobility of OBC has increased relative to General Castes, but not occupational mobility, with the coefficient on the interaction term for educational mobility being positive and significant, while that for occupational mobility is statistically insignificant.

\subsection{Robustness test: intergenerational correlations (IGC) in occupation and education}

An alternate estimate of intergenerational mobility is the IGC, which is the product of the IGRC and the ratio of standard deviation of the parent's educational attainment/occupation rank to the standard deviation of the child's educational attainment/occupational rank (see equation (5) in Appendix B for more details). One well-known weakness of the IGRC is that it does not distinguish between changes in the mean and variance of the outcome distribution and changes in the rank ordering of the outcome distribution. Therefore, if the rank order of outcomes is preserved over generations but the variance of outcomes decreases over time, this may lead to a decrease in the IGRC, suggesting greater mobility. In the case of educational attainment in particular, this may be due to an increase in the overall level of educational attainment in society over time, leading to variance in the educational attainment of sons being less than that of their parent. Such a fall in IGRC, in this case, would not suggest true intergenerational mobility in education.

To guard against this possibility of a spurious finding of greater mobility for son-father pairs compared to father-grandfather pairs, we calculate IGCs for occupation and education by generation for the whole sample and then by group. We present the results in Appendix Tables B1-B4. We find lower IGC estimates in comparison to IGRC estimates between father-son and grandfather-son pairs for occupation,

15 Azam (2015) finds that SC/ST born in the period 1965-84 experience greater occupational mobility compared with the entire 1965-84 cohort or higher castes born in the period 1965-84. 
while for education we obtain lower IGC for grandfather-son pairs but higher for father-son pairs. In comparison to urban areas, we find lower IGC estimates for both occupation and education for rural areas for father-son pairs, while we obtain higher IGC estimates for grandfather-son pairs in occupation but lower for education. In comparison to Hindus, we find higher IGC estimates for occupation but lower for education for the father-son pairs of Muslims, and lower IGC estimates for grandfather-son pairs in occupation but higher in education. In comparison to General Castes, we find lower IGC estimates for $\mathrm{OBC}$ and SC/ST for both occupation and education among both father-son and grandfather-son pairs.

\section{$7 \quad$ Conclusions}

In this paper, we examine three-generation educational and occupational mobility in India using a nationally representative data set - the IHDS - that contains information about education and occupation for three generations. We are able to utilize this unusually rich data set, by developing-country standards, to obtain estimates of son-father and son-grandfather mobility. Further, we exploit the fact that the data spans three generations over time and assess whether multigenerational mobility in India has changed for socially disadvantaged groups and urban residents, relative to their comparators, using an innovative DD method.

Overall, we find that multigenerational mobility has increased over time for education but not for occupation. Educational mobility is higher for the son-father pair than the father-grandfather pair. In contrast, there is little difference in occupational mobility between the son-father and father-grandfather pairs. We also find clear evidence of a 'grandfather' effect - the grandfather's occupational and educational status has an effect on the grandson's occupational and educational status, independent of the father's.

Further, the findings by social group suggest a murky picture of social mobility in India. We find that multigenerational mobility for Muslims in education and occupation has decreased in comparison to that of Hindus. While we find that multigenerational mobility for SC/ST and OBC in education has increased relative to General Castes, we do not find evidence of increased occupational mobility over the three generations for SC/ST/OBC relative to General Castes. Given the roll-out of affirmative action programmes in India since independence for the SC and ST, and for OBC since the early 1990s, the lack of progress on occupational mobility for these socially disadvantaged groups is a matter of policy concern, especially given the high prevalence of poverty among the SC and ST in particular (Gang et al. 2017). Finally, we find that the role of location is equivocal, with more occupational mobility seen for urban residents compared to rural residents over three generations, but less mobility when it comes to education.

Our findings suggest that a multigenerational perspective may provide richer insights into the persistence of economic and social status across generations than the two-generation approach commonly used in the study of social mobility. This may be particularly relevant in the developing-country context, where dynastic effects last for several generations, and where there are deep-rooted social and economic causes of the lack of intergenerational mobility (Iversen et al. 2019). Therefore, an explicit focus on the transmission of outcomes from parent to child without considering the influence of grandparent and further-removed generations may vastly overstate the extent of intergenerational mobility in developing countries.

Our study is not able to assess the causes of limited multigenerational mobility for socially disadvantaged groups in India, and why affirmative action programmes have not delivered social progress in the way they were originally intended to. In the social mobility literature, a range of factors from credit 
constraints on human capital investment, peer effects, and neighbourhood effects have been seen as the drivers of intergenerational persistence of economic and social status (Alesina et al. 2021; Chetty et al. 2016; Iversen et al. 2019). Further research is needed to understand the causal factors behind the strengthening of the inequalities of opportunity that socially disadvantaged groups in India face, even in the context of rapid economic development.

\section{References}

Alesina, A., S. Hohmann, S. Michalopoulos, and E. Papaioannou (2021). 'Intergenerational Mobility in Africa'. Econometrica, 89(1): 1-35. https://doi.org/10.3982/ECTA17018

Armstrong, W.A. (1972). 'The Use of Information About Occupation'. In E.A. Wrigley (ed.), Nineteenth-Century Society: Essays in the Use of Quantitative Methods for the Study of Social Data. Cambridge, Cambridge University Press.

Asher, S., P. Novosad, and C. Rafkin (2020). 'Intergenerational Mobility in India: Estimates from New Methods and Administrative Data'. Available at: www.dartmouth.edu/ novosad/anr-india-mobility.pdf (accessed 9 February 2021).

Azam, M. (2015). 'Intergenerational Occupational Mobility Among Men in India'. Journal of Development Studies, 51(10): 1389-408. https://doi.org/10.1080/00220388.2015.1036040

Azam, M., and V. Bhatt (2015). 'Like Father, Like Son? Intergenerational Educational Mobility in India'. Demography, 52(6): 1929-59. https://doi.org/10.1007/s13524-015-0428-8

Bayly, C.A., and C. Bayly (1999). Empire and Information: Intelligence Gathering and Social Communication in India, 1780-1870. Cambridge: Cambridge University Press.

Becker, G.S., and N. Tomes (1979). 'An Equilibrium Theory of the Distribution of Income and Intergenerational Mobility’. Journal of Political Economy, 87(6): 1153-89. https://doi.org/10.1086/260831

Black, S.E., and P.J. Devereux (2010). 'Recent Developments in Intergenerational Mobility'. Working Paper 15889. Cambridge, MA: NBER. https://doi.org/10.3386/w15889

Blanden, J. (2013). 'Cross-Country Rankings in Intergenerational Mobility: A Comparison of Approaches from Economics and Sociology’. Journal of Economic Surveys, 27(1): 38-73. https://doi.org/10.1111/j.1467-6419. 2011.00690.x

Chetty, R., N. Hendren, and L.F. Katz (2016). 'The Effects of Exposure to Better Neighborhoods on Children: New Evidence from the Moving to Opportunity Experiment'. American Economic Review, 106(4): 855-902. https://doi.org/10.1257/aer.20150572

Chetty, R., N. Hendren, P. Kline, and E. Saez (2014). 'Where Is the Land of Opportunity? The Geography of Intergenerational Mobility in the United States'. Quarterly Journal of Economics, 129(4): 1553-623. https: //doi.org/10.1093/qje/qju022

Corak, M., M.J. Lindquist, and B. Mazumder (2014). 'A Comparison of Upward and Downward Intergenerational Mobility in Canada, Sweden and the United States'. Labour Economics, 30: 185-200. https://doi.org/10.1016/ j.labeco.2014.03.013

Dréze, J., and G.G. Kingdon (2001). 'School Participation in Rural India'. Review of Development Economics, 5(1): 1-24. https://doi.org/10.1111/1467-9361.00103

Erikson, R., and J.H. Goldthorpe (1992). The Constant Flux: A Study of Class Mobility in Industrial Societies. Oxford: Oxford University Press.

Ferreira, F.H., J. Messina, J. Rigolini, L.-F. López-Calva, M.A. Lugo, and R. Vakis (2012). 'Economic Mobility and the Rise of the Latin American Middle Class'. Washington, DC: World Bank. https://doi.org/10.1596/ 978-0-8213-9634-6 
Funjika, P., and R.M. Gisselquist (2020). 'Social Mobility and Inequality Between Groups'. UNU-WIDER Working paper 12/2020. Helsinki: UNU-WIDER. https://doi.org/10.35188/UNU-WIDER/2020/769-9

Gang, I.N., K. Sen, and M.-S. Yun (2011). 'Was the Mandal Commission Right? Differences in Living Standards Between Social Groups'. Economic and Political Weekly, 46(39): 24.

Gang, I.N., K. Sen, and M.-S. Yun (2017). 'Is Caste Destiny? Occupational Diversification Among Dalits in Rural India'. European Journal of Development Research, 29(2): 476-92. https://doi.org/10.1057/ s41287-016-0011-1

Ganzeboom, H.B., and D.J. Treiman (1996). 'Internationally Comparable Measures of Occupational Status for the 1988 International Standard Classification of Occupations'. Social Science Research, 25(3): 201-39. https: //doi.org/10.1006/ssre.1996.0010

Güell, M., J.V. Rodríguez Mora, and G. Solon (2018). 'New Directions in Measuring Intergenerational Mobility: Introduction'. The Economic Journal, 128(612): F335-39. https://doi.org/10.1111/ecoj.12607

Heath, A., and Y. Zhao (2021). 'Rethinking Occupational Mobility in Developing Countries: Conceptual Issues and Empirical Findings'. In V. Iversen, A. Krishna, and K. Sen (eds), Social Mobility in Developing Countries: Concepts, Methods and Determinants. Oxford: Oxford University Press.

Hertz, T., T. Jayasundera, P. Piraino, S. Selcuk, N. Smith, and A. Verashchagina (2008). 'The Inheritance of Educational Inequality: International Comparisons and Fifty-Year Trends'. The BE Journal of Economic Analysis \& Policy, 7(2). https://doi.org/10.2202/1935-1682.1775

Hnatkovska, V., A. Lahiri, and S. Paul (2012). 'Castes and Labor Mobility'. American Economic Journal: Applied Economics, 4(2): 274-307. https://doi.org/10.1257/app.4.2.274

Hnatkovska, V., A. Lahiri, and S.B. Paul (2013). 'Breaking the Caste Barrier Intergenerational Mobility in India'. Journal of Human Resources, 48(2): 435-73. https://doi.org/10.3368/jhr.48.2.435

Iversen, V., A. Krishna, and K. Sen (2019). 'Beyond Poverty Escapes: Social Mobility in Developing Countries: A Review Article'. World Bank Research Observer, 34(2): 239-73. https://doi.org/10.1093/wbro/lkz003

Iversen, V., A. Krishna, and K. Sen (2016). 'Rags to Riches? Intergenerational Occupational Mobility in India'. Technical Report. Manchester: Global Development Institute, University of Manchester.

Krishna, A. (2014). 'Examining the Structure of Opportunity and Social Mobility in India: Who Becomes an Engineer'? Development and Change, 45(1): 1-28. https://doi.org/10.1111/dech.12072

Li, Y. (2021). 'Social Mobility in China: A Case Study of Social Mobility Research in the Global South'. In V. Iversen, A. Krishna, and K. Sen (eds), Social Mobility in Developing Countries: Concepts, Methods and Determinants. Oxford: Oxford University Press.

Long, J., and J. Ferrie (2018). 'Grandfathers Matter(ed): Occupational Mobility Across Three Generations in the US and Britain, 1850-1911'. The Economic Journal, 128(612): F422-45. https://doi.org/10.1111/ecoj.12590

Mohammed, A.S. (2019). 'Does a Good Father Now Have to be Rich? Intergenerational Income Mobility in Rural India'. Labour Economics, 60: 99-114. https://doi.org/10.1016/j.labeco.2019.06.005

Narayan, A., R. Van der Weide, A. Cojocaru, C. Lakner, S. Redaelli, D.G. Mahler, R.G.N. Ramasubbaiah, and S. Thewissen (2018). Fair Progress? Economic Mobility Across Generations Around the World. Washington, DC: World Bank. https://doi.org/10.1596/978-1-4648-1210-1

G. Solon (1999). 'Intergenerational Mobility in the Labor Market'. In O.C. Ashenfelter and D. Card (eds), Handbook of Labor Economics, volume 3. Amsterdam: Elsevier. https://doi.org/10.1016/S1573-4463(99)03010-2

Solon, G. (2004). 'A Model of Intergenerational Mobility Variation Over Time and Place'. In M. Corak (ed.) Generational Income Mobility in North America and Europe. Cambridge: Cambridge University Press. https: //doi.org/10.1017/CBO9780511492549.003

Solon, G. (2014). 'Theoretical Models of Inequality Transmission Across Multiple Generations'. Research in Social Stratification and Mobility, 35: 13-18. https://doi.org/10.1016/j.rssm.2013.09.005 
Solon, G. (2018). 'What Do We Know So Far About Multigenerational Mobility?' The Economic Journal, 128(612): F340-52. https://doi.org/10.1111/ecoj.12495

Wu, X., and D.J. Treiman (2007). 'Inequality and Equality Under Chinese Socialism: The Hukou System and Intergenerational Occupational Mobility'. American Journal of Sociology, 113(2): 415-45. https://doi.org/10. $1086 / 518905$

Zhao, Y., and Y. Li (2017). 'Double Disadvantages: A Study of Ethnic and Hukou Effects on Class Mobility in China ‘(1996-2014). Social Inclusion, 5(1): 5-19. https://doi.org/10.17645/si.v5i1.857 


\section{Appendix A: Extra tables}

\section{A1 Occupational mobility}

Table A1: Occupational mobility between G1 and G2

\begin{tabular}{|c|c|c|c|c|c|c|c|c|c|c|c|c|c|c|}
\hline \multirow[t]{3}{*}{ Generation 1} & \multicolumn{14}{|c|}{ Generation 2} \\
\hline & \multicolumn{2}{|c|}{ Professionals } & \multicolumn{2}{|c|}{ Clerical } & \multicolumn{2}{|c|}{ Farmers } & \multicolumn{2}{|c|}{ High-skilled labour } & \multicolumn{2}{|c|}{ Low-skilled labour } & \multicolumn{2}{|c|}{ Agri. \& other labour } & \multicolumn{2}{|c|}{ Total } \\
\hline & $N$ & Row \% & $N$ & Row \% & $N$ & Row \% & $N$ & Row \% & $N$ & Row \% & $N$ & Row \% & $N$ & Row \% \\
\hline Professionals & 291 & 39.1 & 193 & 25.9 & 79 & 10.6 & 69 & 9.3 & 55 & 7.4 & 58 & 7.8 & 745 & 100.0 \\
\hline Clerical & 223 & 14.4 & 851 & 54.9 & 87 & 5.6 & 129 & 8.3 & 156 & 10.1 & 103 & 6.6 & 1,549 & 100.0 \\
\hline Farmers & 555 & 5.7 & 934 & 9.6 & 4,501 & 46.3 & 518 & 5.3 & 607 & 6.2 & 2,598 & 26.7 & 9,713 & 100.0 \\
\hline High-skilled labour & 123 & 12.4 & 175 & 17.6 & 97 & 9.8 & 370 & 37.3 & 121 & 12.2 & 107 & 10.8 & 993 & 100.0 \\
\hline Low-skilled labour & 120 & 7.7 & 217 & 13.9 & 84 & 5.4 & 142 & 9.1 & 762 & 48.8 & 235 & 15.1 & 1,560 & 100.0 \\
\hline Agri. \& other labour & 189 & 3.8 & 473 & 9.4 & 618 & 12.3 & 293 & 5.8 & 566 & 11.2 & 2,893 & 57.5 & 5,032 & 100.0 \\
\hline Total & 1,501 & 7.7 & 2,843 & 14.5 & 5,466 & 27.9 & 1,521 & 7.8 & 2,267 & 11.6 & 5,994 & 30.6 & 19,592 & 100.0 \\
\hline
\end{tabular}

Source: authors' compilation based on IHDS data.

Table A2: Occupational mobility between G2 and G3

Generation $2 \quad$ Generation 3

\begin{tabular}{|c|c|c|c|c|c|c|c|c|c|c|c|c|c|c|}
\hline \multirow[t]{3}{*}{ Generation 2} & \multicolumn{14}{|c|}{ Generation 3} \\
\hline & \multicolumn{2}{|c|}{ Professionals } & \multicolumn{2}{|c|}{ Clerical } & \multicolumn{2}{|c|}{ Farmers } & \multicolumn{2}{|c|}{ High-skilled labour } & \multicolumn{2}{|c|}{ Low-skilled labour } & \multicolumn{2}{|c|}{ Agri. \& other labour } & \multicolumn{2}{|c|}{ Total } \\
\hline & $N$ & Row \% & $N$ & Row \% & $N$ & Row \% & $N$ & Row \% & $N$ & Row \% & $\mathrm{N}$ & Row \% & $\mathrm{N}$ & Row \% \\
\hline Professionals & 349 & 46.1 & 127 & 16.8 & 91 & 12.0 & 68 & 9.0 & 65 & 8.6 & 57 & 7.5 & 757 & 100.0 \\
\hline Clerical & 188 & 10.8 & 837 & 48.1 & 132 & 7.6 & 166 & 9.5 & 213 & 12.2 & 203 & 11.7 & 1,739 & 100.0 \\
\hline Farmers & 369 & 8.3 & 442 & 10.0 & 1,743 & 39.4 & 351 & 7.9 & 411 & 9.3 & 1,112 & 25.1 & 4,428 & 100.0 \\
\hline High-skilled labour & 89 & 9.5 & 168 & 17.9 & 90 & 9.6 & 308 & 32.9 & 145 & 15.5 & 136 & 14.5 & 936 & 100.0 \\
\hline Low-skilled labour & 94 & 6.3 & 202 & 13.6 & 76 & 5.1 & 184 & 12.3 & 672 & 45.1 & 262 & 17.6 & 1,490 & 100.0 \\
\hline Agri. \& other labour & 188 & 4.1 & 338 & 7.3 & 399 & 8.6 & 359 & 7.8 & 563 & 12.2 & 2,773 & 60.0 & 4,620 & 100.0 \\
\hline Total & 1,277 & 9.1 & 2,114 & 15.1 & 2,531 & 18.1 & 1,436 & 10.3 & 2,069 & 14.8 & 4,543 & 32.5 & 13,970 & 100.0 \\
\hline
\end{tabular}

Source: authors' compilation based on IHDS data. 
Table A3: Occupational mobility between G1 and G3

\begin{tabular}{|c|c|c|c|c|c|c|c|c|c|c|c|c|c|c|}
\hline \multirow[t]{3}{*}{ Generation 1} & \multicolumn{14}{|c|}{ Generation 3} \\
\hline & \multicolumn{2}{|c|}{ Professionals } & \multicolumn{2}{|c|}{ Clerical } & \multicolumn{2}{|c|}{ Farmers } & \multicolumn{2}{|c|}{ High-skilled labour } & \multicolumn{2}{|c|}{ Low-skilled labour } & \multicolumn{2}{|c|}{ Agri. \& other labour } & \multicolumn{2}{|c|}{ Total } \\
\hline & $N$ & Row \% & $N$ & Row \% & $N$ & Row \% & $N$ & Row \% & $N$ & Row \% & $\mathrm{N}$ & Row \% & $\mathrm{N}$ & Row \% \\
\hline Professionals & 244 & 36.4 & 159 & 23.7 & 45 & 6.7 & 81 & 12.1 & 84 & 12.5 & 58 & 8.6 & 671 & 100.0 \\
\hline Clerical & 271 & 18.9 & 652 & 45.5 & 47 & 3.3 & 141 & 9.8 & 178 & 12.4 & 143 & 10.0 & 1,432 & 100.0 \\
\hline Farmers & 831 & 9.2 & 1,184 & 13.2 & 2,522 & 28.1 & 736 & 8.2 & 1,023 & 11.4 & 2,689 & 29.9 & 8,985 & 100.0 \\
\hline High-skilled labour & 141 & 16.1 & 207 & 23.6 & 50 & 5.7 & 219 & 25.0 & 144 & 16.4 & 115 & 13.1 & 876 & 100.0 \\
\hline Low-skilled labour & 157 & 10.5 & 254 & 17.0 & 52 & 3.5 & 191 & 12.8 & 569 & 38.1 & 271 & 18.1 & 1,494 & 100.0 \\
\hline Agri. \& other labour & 328 & 7.1 & 535 & 11.5 & 280 & 6.0 & 522 & 11.3 & 749 & 16.2 & 2,221 & 47.9 & 4,635 & 100.0 \\
\hline Total & 1,972 & 10.9 & 2,991 & 16.5 & 2,996 & 16.6 & 1,890 & 10.4 & 2,747 & 15.2 & 5,497 & 30.4 & 18,093 & 100.0 \\
\hline
\end{tabular}

Source: authors' compilation based on IHDS data.

\section{A2 Educational mobility}

Table A4: Educational mobility between G1 and G2

\begin{tabular}{|c|c|c|c|c|c|c|c|c|c|c|c|c|c|c|c|c|}
\hline \multirow[t]{3}{*}{ Generation 1} & \multicolumn{16}{|c|}{ Generation 2} \\
\hline & \multicolumn{2}{|c|}{$<2 \mathrm{yrs}$} & \multicolumn{2}{|c|}{$2-4 \mathrm{yrs}$} & \multicolumn{2}{|c|}{ Primary } & \multicolumn{2}{|c|}{ Middle } & \multicolumn{2}{|c|}{ Secondary } & \multicolumn{2}{|c|}{ Higher secondary } & \multicolumn{2}{|c|}{ Higher ed. } & \multicolumn{2}{|c|}{ Total } \\
\hline & $N$ & Row \% & $N$ & Row \% & $N$ & Row \% & $N$ & Row \% & $N$ & Row \% & $N$ & Row \% & $N$ & Row \% & $N$ & Row \% \\
\hline$<2$ yrs & 6,970 & 43.0 & 2,038 & 12.6 & 1,574 & 9.7 & 2,263 & 14.0 & 2,165 & 13.4 & 696 & 4.3 & 491 & 3.0 & 16,197 & 100.0 \\
\hline $2-4 \mathrm{yrs}$ & 295 & 10.4 & 625 & 22.0 & 296 & 10.4 & 522 & 18.4 & 653 & 23.0 & 234 & 8.2 & 212 & 7.5 & 2,837 & 100.0 \\
\hline Primary & 232 & 10.1 & 189 & 8.2 & 393 & 17.1 & 470 & 20.5 & 546 & 23.8 & 209 & 9.1 & 256 & 11.2 & 2,295 & 100.0 \\
\hline Middle & 98 & 5.7 & 81 & 4.7 & 105 & 6.2 & 486 & 28.5 & 476 & 27.9 & 190 & 11.1 & 270 & 15.8 & 1,706 & 100.0 \\
\hline Secondary & 42 & 3.1 & 22 & 1.6 & 40 & 2.9 & 109 & 8.0 & 649 & 47.8 & 184 & 13.6 & 311 & 22.9 & 1,357 & 100.0 \\
\hline Higher secondary & 7 & 2.0 & 3 & 0.9 & 5 & 1.4 & 16 & 4.6 & 87 & 25.1 & 124 & 35.8 & 104 & 30.1 & 346 & 100.0 \\
\hline Higher ed. & 77 & 12.8 & 31 & 5.1 & 17 & 2.8 & 23 & 3.8 & 115 & 19.1 & 68 & 11.3 & 272 & 45.1 & 603 & 100.0 \\
\hline Total & 7,721 & 30.5 & 2,989 & 11.8 & 2,430 & 9.6 & 3,889 & 15.3 & 4,691 & 18.5 & 1,705 & 6.7 & 1,916 & 7.6 & 25,341 & 100.0 \\
\hline
\end{tabular}

Source: authors' compilation based on IHDS data. 
Table A5: Educational mobility between G2 and G3

\begin{tabular}{|c|c|c|c|c|c|c|c|c|c|c|c|c|c|c|c|c|}
\hline \multirow[t]{3}{*}{ Generation 2} & \multicolumn{16}{|c|}{ Generation 3} \\
\hline & \multicolumn{2}{|c|}{$<2$ yrs } & \multicolumn{2}{|c|}{$2-4 \mathrm{yrs}$} & \multicolumn{2}{|c|}{ Primary } & \multicolumn{2}{|c|}{ Middle } & \multicolumn{2}{|c|}{ Secondary } & \multicolumn{2}{|c|}{ Higher secondary } & \multicolumn{2}{|c|}{ Higher ed. } & \multicolumn{2}{|c|}{ Total } \\
\hline & $N$ & Row \% & $N$ & Row \% & $N$ & Row \% & $N$ & Row \% & $N$ & Row \% & $N$ & Row \% & $N$ & Row \% & N & Row \% \\
\hline$<2 \mathrm{yrs}$ & 1,101 & 14.3 & 466 & 6.0 & 612 & 7.9 & 1,542 & 20.0 & 1,484 & 19.2 & 787 & 10.2 & 1,729 & 22.4 & 7,721 & 100.0 \\
\hline $2-4$ yrs & 147 & 4.9 & 189 & 6.3 & 165 & 5.5 & 531 & 17.8 & 790 & 26.4 & 427 & 14.3 & 740 & 24.8 & 2,989 & 100.0 \\
\hline Primary & 91 & 3.7 & 71 & 2.9 & 170 & 7.0 & 434 & 17.9 & 600 & 24.7 & 356 & 14.7 & 708 & 29.1 & 2,430 & 100.0 \\
\hline Middle & 75 & 1.9 & 93 & 2.4 & 138 & 3.5 & 570 & 14.7 & 984 & 25.3 & 773 & 19.9 & 1,256 & 32.3 & 3,889 & 100.0 \\
\hline Secondary & 67 & 1.4 & 28 & 0.6 & 59 & 1.3 & 311 & 6.6 & 1,003 & 21.4 & 1,188 & 25.3 & 2,035 & 43.4 & 4,691 & 100.0 \\
\hline Higher secondary & 11 & 0.6 & 9 & 0.5 & 21 & 1.2 & 71 & 4.2 & 221 & 13.0 & 424 & 24.9 & 948 & 55.6 & 1,705 & 100.0 \\
\hline Higher ed. & 5 & 0.3 & 4 & 0.2 & 4 & 0.2 & 35 & 1.8 & 162 & 8.5 & 339 & 17.7 & 1,367 & 71.3 & 1,916 & 100.0 \\
\hline Total & 1,497 & 5.9 & 860 & 3.4 & 1,169 & 4.6 & 3,494 & 13.8 & 5,244 & 20.7 & 4,294 & 16.9 & 8,783 & 34.7 & 25,341 & 100.0 \\
\hline
\end{tabular}

Source: authors' compilation based on IHDS data.

Table A6: Educational mobility between $\mathrm{G} 1$ and $\mathrm{G} 3$

\begin{tabular}{|c|c|c|c|c|c|c|c|c|c|c|c|c|c|c|c|c|}
\hline \multirow[t]{3}{*}{ Generation 1} & \multicolumn{16}{|c|}{ Generation 3} \\
\hline & \multicolumn{2}{|c|}{$<2$ yrs } & \multicolumn{2}{|c|}{$2-4$ yrs } & \multicolumn{2}{|c|}{ Primary } & \multicolumn{2}{|c|}{ Middle } & \multicolumn{2}{|c|}{ Secondary } & \multicolumn{2}{|c|}{ Higher secondary } & \multicolumn{2}{|c|}{ Higher ed. } & \multicolumn{2}{|c|}{ Total } \\
\hline & $N$ & Row \% & $N$ & Row \% & $N$ & Row \% & $N$ & Row \% & $N$ & Row \% & $N$ & Row \% & $N$ & Row \% & $N$ & Row \% \\
\hline$<2$ yrs & 1,335 & 8.2 & 690 & 4.3 & 903 & 5.6 & 2,641 & 16.3 & 3,406 & 21.0 & 2,526 & 15.6 & 4,696 & 29.0 & 16,197 & 100.0 \\
\hline $2-4$ yrs & 59 & 2.1 & 84 & 3.0 & 114 & 4.0 & 343 & 12.1 & 712 & 25.1 & 520 & 18.3 & 1,005 & 35.4 & 2,837 & 100.0 \\
\hline Primary & 42 & 1.8 & 41 & 1.8 & 87 & 3.8 & 242 & 10.5 & 471 & 20.5 & 416 & 18.1 & 996 & 43.4 & 2,295 & 100.0 \\
\hline Middle & 30 & 1.8 & 29 & 1.7 & 36 & 2.1 & 150 & 8.8 & 308 & 18.1 & 350 & 20.5 & 803 & 47.1 & 1,706 & 100.0 \\
\hline Secondary & 11 & 0.8 & 11 & 0.8 & 15 & 1.1 & 72 & 5.3 & 212 & 15.6 & 304 & 22.4 & 732 & 53.9 & 1,357 & 100.0 \\
\hline Higher secondary & 3 & 0.9 & 0 & 0.0 & 4 & 1.2 & 7 & 2.0 & 45 & 13.0 & 85 & 24.6 & 202 & 58.4 & 346 & 100.0 \\
\hline Higher ed. & 17 & 2.8 & 5 & 0.8 & 10 & 1.7 & 39 & 6.5 & 90 & 14.9 & 93 & 15.4 & 349 & 57.9 & 603 & 100.0 \\
\hline Total & 1,497 & 5.9 & 860 & 3.4 & 1,169 & 4.6 & 3,494 & 13.8 & 5,244 & 20.7 & 4,294 & 16.9 & 8,783 & 34.7 & 25,341 & 100.0 \\
\hline
\end{tabular}

Source: authors' compilation based on IHDS data. 
Table A7: Occupational codes

\author{
PROFESSIONAL, TECHNICAL, AND \\ RELATED WORKERS \\ 00 Physical Scientists \\ 01 Physical Science Technicians \\ 02 Architects, Engineers, Technologists, and Surveyors \\ 03 Engineering Technicians \\ 04 Aircraft and Ships Officers \\ 05 Life Scientists \\ 06 Life Science Technicians \\ 07 Physicians and Surgeons (Allopathic Dental and Veterinary \\ Surgeons) \\ 08 Nursing and Other Medical and Health Technicians \\ 09 Scientific, Medical, and Technical Persons, Othe \\ 10 Mathematicians, Statisticians, and Related Workers \\ 11 Economists and Related Workers \\ 12 Accountants, Auditors, and Related Workers \\ 13 Social Scientists and Related Workers \\ 14 Jurists \\ 15 Teachers \\ 16 Poets, Authors, Journalists, and Related Workers \\ 17 Sculptors, Painters, Photographers, and Related Creative Artists \\ 18 Composers and Performing Artists \\ 19 Professional Workers, n.e.c.
}

\section{ADMINISTRATIVE, EXECUTIVE, AND}

MANAGERIAL WORKERS

20 Elected and Legislative Officials

21 Administrative and Executive Officials, Government and Local Bodies

22 Working Proprietors, Directors and Managers, Wholesale and

Retail Trade

23 Directors and Managers, Financial Institutions

24 Working Proprietors, Directors and Managers Mining,

Construction, Manufacturing, and Related Concerns

25 Working Proprietors, Directors, Managers and Related

Executives, Transport, Storage, and Communication

26 Working Proprietors, Directors and Managers, Other Service

29 Administrative, Executive and Managerial Workers, n.e.c.

\section{CLERICAL AND RELATED WORKERS}

30 Clerical and Other Supervisors

31 Village Officials

32 Stenographers, Typists, and Card and Tape Punching Operators

33 Book-keepers, Cashiers, and Related Workers

34 Computing Machine Operators

35 Clerical and Related Workers, n.e.c.

36 Transport and Communication Supervisors

37 Transport Conductors and Guards

38 Mail Distributors and Related Workers

39 Telephone and Telegraph Operators

\section{SALES WORKERS}

40 Merchants and Shopkeepers, Wholesale and Retail Trade

41 Manufacturers, Agents

42 Technical Salesmen and Commercial Travellers

43 Salesmen, Shop Assistants, and Related Workers

44 Insurance, Real Estate, Securities, and Business Service

Salesmen and Auctioneers

45 Money Lenders and Pawn Brokers

49 Sales Workers, n.e.c.

\section{SERVICE WORKERS}

50 Hotel and Restaurant Keepers

51 House Keepers, Matron, and Stewards (Domestic and Institutional) 52 Cooks, Waiters, Bartenders, and Related Worker (Domestic and Institutional)

\section{SERVICE WORKERS}

53 Maids and Other House Keeping Service Workers n.e.c. 54 Building Caretakers, Sweepers, Cleaners, and Related Workers 55 Launderers, Dry-cleaners, and Pressers

56 Hair Dressers, Barbers, Beauticians, and Related Workers

57 Protective Service Workers

59 Service Workers, n.e.c.

FARMERS, FISHERMEN, HUNTERS, LOGGERS,

AND RELATED WORKERS

60 Farm Plantation, Dairy and Other Managers and Supervisors

61 Cultivators

62 Farmers other than Cultivators

63 Agricultural Labourers

64 Plantation Labourers and Related Workers

65 Other Farm Workers

66 Forestry Workers

67 Hunters and Related Workers

68 Fishermen and Related Workers

PRODUCTION AND RELATED WORKERS, TRANSPORT

EQUIPMENT OPERATORS AND LABOURERS

71 Miners, Quarrymen, Well Drillers, and Related Workers

72 Metal Processors

73 Wood Preparation Workers and Paper Makers

74 Chemical Processors and Related Workers

75 Spinners, Weavers, Knitters, Dyers, and Related Workers

76 Tanners, Fellmongers, and Pelt Dressers

77 Food and Beverage Processors

78 Tobacco Preparers and Tobacco Product Makers

79 Tailors, Dress Makers, Sewers, Upholsterers, and Related Workers

80 Shoe Makers and Leather Goods Makers

81 Carpenters, Cabinet and Related Wood Workers

82 Stone Cutters and Carvers

83 Blacksmiths, Tool Makers, and Machine Tool Operators

84 Machinery Fitters, Machine Assemblers, and Precision Instrument Makers (except Electrical)

85 Electrical Fitters and Related Electrical and Electronic Workers

86 Broadcasting Station and Sound Equipment Operators and Cinema Projectionists

87 Plumbers, Welders, Sheet Metal, and Structural Metal Preparers and Erectors

88 Jewellery and Precious Metal Workers and Metal Engravers (Except

Printing)

89 Glass Formers, Potters, and Related Workers

90 Rubber and Plastic Product Makers

91 Paper and Paper Board Products Makers

92 Printing and Related Workers

93 Painters

94 Production and Related Workers, n.e.c.

95 Bricklayers and Other Constructions Workers

96 Stationery Engines and Related Equipment Operators, Oilers and Greasers

97 Material Handling and Related Equipment Operators, Loaders and Unloaders

98 Transport Equipment Operators

99 Labourers, n.e.c.

\section{WORKERS NOT CLASSIFIED BY OCCUPATIONS}

X0 New Workers Seeking Employment

X1 Workers Reporting Occupations Unidentifiable

X9 Workers Not Reporting Any Occupation

AA Housewife/Household work

BB Student/Too Young to Work

CC Retired/Too Old to Work

DD Disabled/Unfit to Work

EE Out of Labour Force n.e.

Source: authors' compilation based on the NCO. 


\section{Appendix B: IGC}

To obtain the IGC estimate, we adjust the IGRC estimated in equation 3 by the ratio of standard deviation of (grand) parental education (occupation) to that of the (grand) children's education (occupation):

$$
\begin{array}{r}
I G C_{\text {Parent }}: \hat{\rho_{1}}=\hat{\beta_{1}} *\left(\frac{\sigma_{p}}{\sigma_{c}}\right), \\
I G C_{\text {Grandparent }}: \hat{\rho_{2}}=\hat{\beta_{2}} *\left(\frac{\sigma_{g}}{\sigma_{c}}\right)
\end{array}
$$

where $\sigma_{g}, \sigma_{p}$, and $\sigma_{c}$ are the standard deviations of the grandparent, parent, and son's outcomes, respectively. The parameter of interest is $\hat{\rho}$.

Table B1: Intergenerational correlation

\begin{tabular}{lcccc}
\hline & G3 occ. $\geq 18$ & G3 occ. $\geq 21$ & G3 edu. $\geq 18$ & G3 edu. $\geq 21$ \\
\hline Gen 2 & $0.402^{* * *}$ & $0.403^{* * *}$ & $0.381^{* * *}$ & $0.387^{* * *}$ \\
& $(0.00824)$ & $(0.00989)$ & $(0.00641)$ & $(0.00732)$ \\
Gen 1 & $0.105^{* * *}$ & $0.0988^{* * *}$ & $0.0562^{* * *}$ & $0.0584^{* * *}$ \\
& $(0.00822)$ & $(0.00988)$ & $(0.00641)$ & $(0.00728)$ \\
\hline Observations & 13907 & 10333 & 25341 & 19359 \\
\hline
\end{tabular}

Note: standard errors in parentheses are calculated with the delta method using the nlcom command in STATA. * $p<0.05$, ${ }^{* *} p<0.01,{ }^{* * *} p<0.001$.

Source: authors' compilation based on IHDS data.

Table B2: Intergenerational correlation: location

\begin{tabular}{lcccc}
\hline & G3 occ. urban & G3 occ. rural & G3 edu. urban & G3 edu. rural \\
\hline Gen 2 & $0.437^{* * *}$ & $0.352^{* * *}$ & $0.461^{* * *}$ & $0.328^{* * *}$ \\
& $(0.0162)$ & $(0.00971)$ & $(0.0103)$ & $(0.00788)$ \\
Gen 1 & $0.109^{* * *}$ & $0.115^{* * *}$ & $0.0680^{* * *}$ & $0.0460^{* * *}$ \\
& $(0.0161)$ & $(0.00964)$ & $(0.0103)$ & $(0.00788)$ \\
\hline Observations & 3581 & 10326 & 8890 & 16451 \\
\hline
\end{tabular}

Note: standard errors in parentheses are calculated with the delta method using the nlcom command in STATA. * $p<0.05$, ${ }^{\star *} p<0.01,{ }^{* * *} p<0.001$.

Source: authors' compilation based on IHDS data.

Table B3: Intergenerational correlation: religion

\begin{tabular}{lcccc}
\hline & G3 occ. Hindu & G3 occ. Muslim & G3 edu. Hindu & G3 edu. Muslim \\
\hline Gen 2 & $0.399^{* * *}$ & $0.405^{* * *}$ & $0.372^{* * *}$ & $0.362^{* * *}$ \\
& $(0.00916)$ & $(0.0232)$ & $(0.00722)$ & $(0.0173)$ \\
Gen 1 & $0.107^{* * *}$ & $0.0652^{* *}$ & $0.0613^{* * *}$ & $0.0637^{* * *}$ \\
& $(0.00916)$ & $(0.0232)$ & $(0.00722)$ & $(0.0173)$ \\
\hline Observations & 11317 & 1742 & 20242 & 3376 \\
\hline
\end{tabular}

Note: standard errors in parentheses are calculated with the delta method using the nlcom command in STATA. ${ }^{*} p<0.05$, ${ }^{* *} p<0.01,{ }^{* * *} p<0.001$.

Source: authors' compilation based on IHDS data. 
Table B4: Intergenerational correlation: caste

\begin{tabular}{lcccccc}
\hline & G3 occ. general & G3 occ. OBC & G3 occ. SC/ST & G3 edu. general & G3 edu. OBC & G3 edu. SC/ST \\
\hline Gen 2 & $0.391^{* * *}$ & $0.390^{* * *}$ & $0.331^{* * *}$ & $0.409^{* * *}$ & $0.365^{* * *}$ & $0.319^{* * *}$ \\
& $(0.0157)$ & $(0.0126)$ & $(0.0158)$ & $(0.0115)$ & $(0.00964)$ & $(0.0123)$ \\
Gen 1 & $0.104^{* * *}$ & $0.0698^{* * *}$ & $0.0748^{* * *}$ & $0.0698^{* * *}$ & $0.0423^{* * *}$ & $0.0379^{* *}$ \\
& $(0.0164)$ & $(0.0126)$ & $(0.0152)$ & $(0.0115)$ & $(0.00964)$ & $(0.0123)$ \\
\hline Observations & 3847 & 5984 & 4052 & 7847 & 10689 & 6731 \\
\hline
\end{tabular}

Note: standard errors in parentheses are calculated with the delta method using the nlcom command in STATA. ${ }^{*} p<0.05$, ${ }^{* *} p<0.01,{ }^{* * *} p<0.001$.

Source: authors' compilation based on IHDS data. 
Appendix C: Graphs

Figure C1: Educational attainment over generations across states
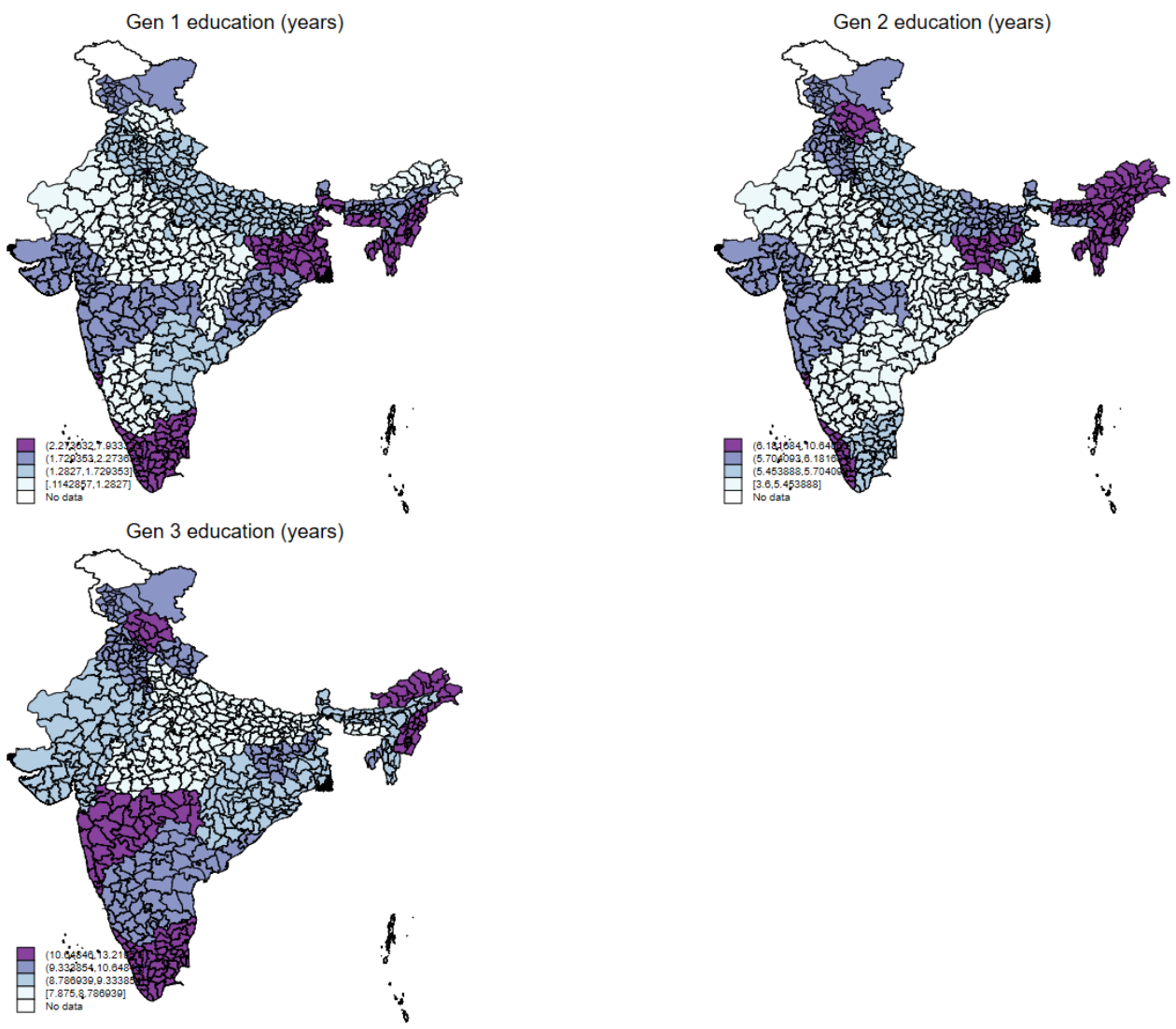

Source: authors' compilation based on IHDS data. 
Figure C2: Occupational attainment over generations across states
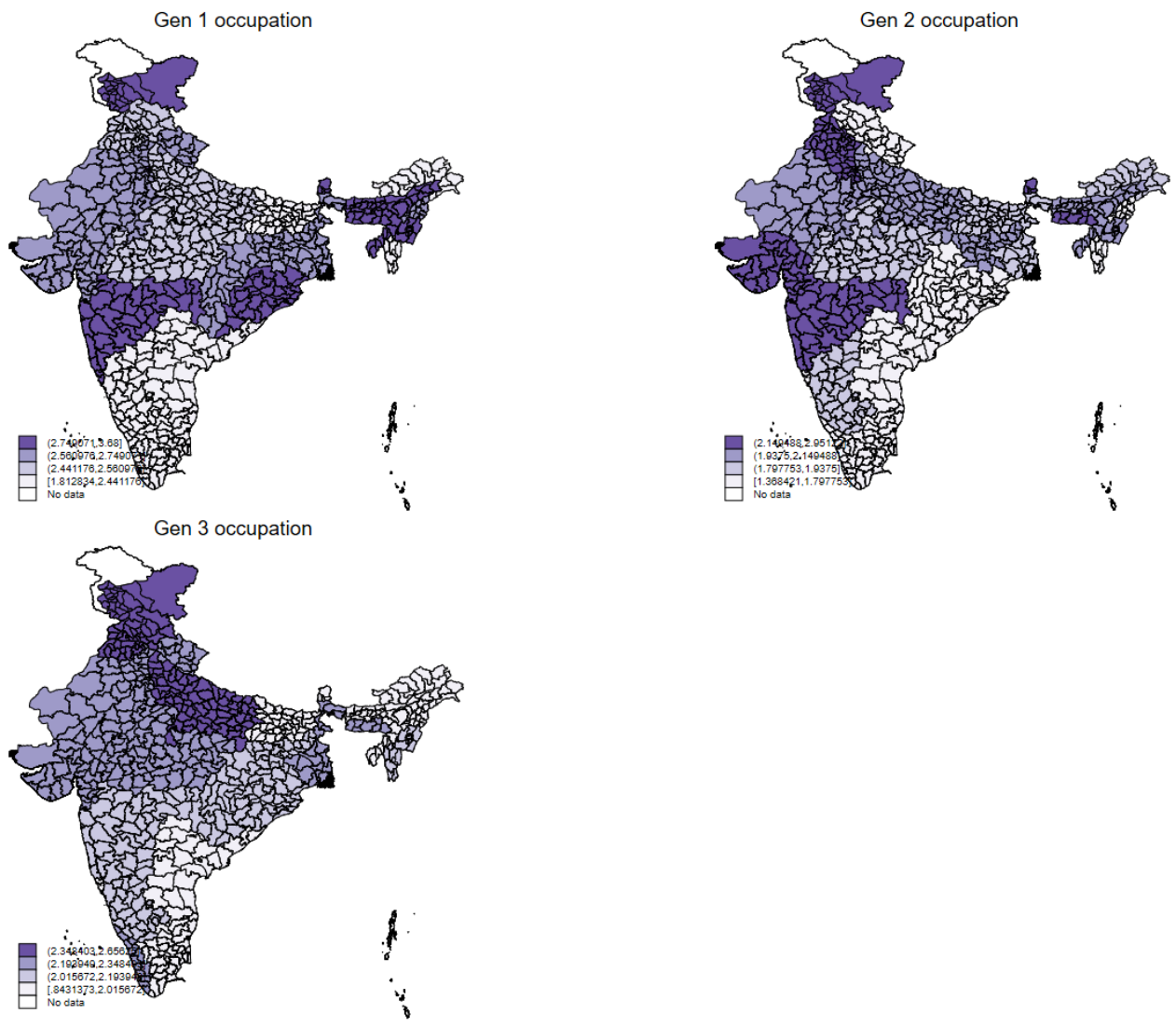

Source: authors' compilation based on IHDS data. 